\title{
DOES THE WELFARE STATE AFFECT INDIVIDUAL ATTITUDES TOWARD IMMIGRANTS? EVIDENCE ACROSS COUNTRIES
}

\author{
Giovanni Facchini and Anna Maria Mayda*
}

\begin{abstract}
This paper analyzes welfare-state determinants of individual attitudes toward immigrants - within and across countries-and their interaction with labor market drivers of preferences. We consider two mechanisms through which a redistributive welfare system might adjust as a result of immigration. Under the first model, immigration has a larger impact on high-income individuals, while under the second one lowincome individuals are those most affected. Individual attitudes are consistent with the first welfare-state model and with labor market determinants. In countries where immigration is unskilled, income is negatively correlated with pro-immigration preferences, while skill is positively correlated with them. These relationships are reversed in economies characterized by skilled migration.
\end{abstract}

We must end welfare state subsidies for illegal immigrants ... This alienates taxpayers and breeds suspicion of immigrants, even though the majority of them work very hard. Without a welfare state, we would know that everyone coming to America wanted to work hard and support himself.-Rep. Ron Paul, R-Texas ${ }^{1}$

\section{Introduction}

$\mathrm{N}_{\mathrm{p}}^{\mathrm{o}}$ O OTHER facet of globalization has spurred as much public debate as the movement of workers across national boundaries. Even within ideologically homogeneous groups, often contradictory positions emerge. U.S. labor unions, although now officially welcoming Latino and immigrant members, ${ }^{2}$ see their rank and file oppose growing inflows of unskilled foreign workers. Similarly, while Silicon Valley entrepreneurs trooped in front of Congress in 1998 to obtain an increase in the number of H-1B visas, many conservative groups fear immigration and have fiercely opposed the 2004 proposal of the Bush administration to grant illegal immigrants legal status as guest workers.

A large portion of the discussion is fueled by the incomedistribution consequences of immigration. Native workers are concerned about new immigrants of similar skill levels

Received for publication December 17, 2006. Revision accepted for publication November 9, 2007.

* Universitá degli Studi di Milano, Erasmus University of Rotterdam, CEPR, CES-Ifo, and Centro Studi Luca d'Agliano; Georgetown University Economics Department and SFS, CEPR, IZA, CReAM, and Centro Studi Luca d'Agliano.

Very useful comments were provided by Marc Busch, Klaus Desmet, Pravin Krishna, Darren Lubotsky, Rod Ludema, Kevin O'Rourke, Lant Pritchett, Sarah Reber, Cecilia Testa, and by seminar audiences at the University of Ancona, CORE Universite Catholique de Louvain, ECARES, George Washington University, Johns Hopkins-SAIS, Mediocredito Centrale, Queen Mary-University of London, Syracuse University, Trinity College Dublin, Warwick, IADB, the 2006 AEA Meetings in Boston, the 2006 CReAM Conference on Migration at University College London, the CES-Ifo conference on the Global Economy, the 2006 CEPR ERWIT conference in Vienna, and the 2006 Midwest International Trade Meetings in East Lansing.

${ }^{1}$ Cited from U.S. Fed News, August 8, 2005.

${ }^{2}$ See Watts (2002). because they are wary of increasing competition, ${ }^{3}$ inducing downward pressure on their incomes and contributing to the growing feeling of uncertainty that accompanies globalization. ${ }^{4}$ On the other hand, native workers welcome immigrants who complement them in the labor market. A second and not less important dimension of the debate is represented by the welfare-state channel. In fact, the very existence in many destination countries of redistributive social insurance programs is likely to have a magnetic effect on some unskilled immigrants, interested not only in new job opportunities, but also in the benefits that come in the form of subsidized healthcare, unemployment compensation, or provisions concerning dependants. ${ }^{5}$ While this type of labor flow is likely to represent a net burden for the public finances of the host countries, in general migration can have the opposite effect on the welfare state, for example, when migrants are skilled. Regardless of whether immigration represents a net cost or benefit for public finances, adjustments in the redistribution carried out by the welfare state are unavoidable. Importantly, this paper shows that the type of response carried out by the welfare state is a key determinant of the effect of immigration on various subgroups of the population and, as a consequence, on individual opinions about migration. To shed light on these issues, we develop a theoretical framework of individual attitudes toward migration in which the labor market and welfare state interact with each other as drivers of opinions.

The analysis of the labor market channel follows the previous literature. ${ }^{6}$ We focus on two factors of production, skilled and unskilled labor, and consider cases in which migrants are either less or more skilled than native workers. We show that the probability that an individual is proimmigration is an increasing (decreasing) function of her skill in countries where the relative skill composition of natives to immigrants is high (low). The intuition is that when immigrants are unskilled, they reduce the relative supply of skilled to unskilled labor in the economy, thus increasing the skilled wage and reducing the unskilled wage. The opposite is true when immigrants are more skilled than natives.

More importantly, in our model we consider two alternative adjustment mechanisms through which the welfare state

\footnotetext{
${ }^{3}$ For instance, the threatening "Polish plumber" has been often mentioned as heavily conditioning the French vote against the new European constitution.

${ }^{4}$ See for instance Rodrik (1997)

${ }^{5}$ See Borjas (1999a), and Boeri, Hanson, and McCormick (2002).

${ }^{6}$ See Borjas (1999b), Scheve and Slaughter (2001), Mayda (2006), O'Rourke and Sinnott (2006).
} 
of the host country can respond to an inflow of immigrants. ${ }^{7}$ In each welfare-state model, we analyze the effect of an inflow of either unskilled or skilled foreign workers. While the former represent a net cost for the welfare state, the latter are likely to make a positive net contribution to the system. ${ }^{8}$ In the first welfare-state model we assume that, following immigration, the value of per capita benefits is unaffected, while welfare costs (tax rates) adjust in order to balance the government's budget (tax adjustment model). Assuming a redistributive fiscal system, we find that highincome individuals are more negatively affected by unskilled immigration than low-income individuals-as they bear most of the additional cost to the welfare system. However, they are more positively affected than lowincome individuals by skilled immigration. In general, in the tax adjustment model, immigration has a larger impact on individuals at the top of the income distribution. In the second welfare-state model, we assume instead that the adjustment induced by immigration occurs through changes in per capita welfare benefits, as tax rates are kept constant (benefit adjustment model). Under these assumptions, if immigrants are unskilled relative to natives, the burden of the worsened fiscal position of the welfare state falls relatively more on individuals at the bottom of the income distribution. In other words, unskilled immigration negatively affects low-income households to a greater extent than their high-income counterparts. If immigration is instead skilled-and is thus likely to relax the government's budget constraint-it will lead to an improvement in the position of low-income workers through the welfare-state channel that is greater than for high-income individuals. In general, in the benefit adjustment model, it is low-income individuals who are most affected by immigration. To summarize, in the tax adjustment model we expect individual income to be negatively correlated with pro-immigration preferences in countries where the skill composition of natives relative to immigrants is high (unskilled immigration), and positively correlated otherwise (skilled immigration). In the benefit adjustment model, we expect the opposite type of cross-country pattern. ${ }^{9}$

Our empirical analysis, carried out using the $1995 \mathrm{Na}-$ tional Identity Module of the International Social Survey

\footnotetext{
${ }^{7}$ We assume that individuals take as given one of the two adjustments of the welfare state, that is respondents do not perceive the adjustment type as endogenous to immigration. Therefore, ours is not a political-economy model and is best suited for a short-run analysis. See, among others, Razin, Sadka, and Swagel (2002) and Ortega (2005) for long-run politicaleconomy models of migration and the welfare state.

${ }^{8}$ As will become clearer in section III, skilled migrant workers are not necessarily net contributors to the welfare state, because differently from their native counterparts, they are endowed only with labor-related assets.

${ }^{9}$ In order to simplify the analysis, we only consider two extreme cases in terms of the adjustment of the welfare state. However, it is possible to extend this framework and consider intermediate cases, where both tax rates and per capita benefits adjust. In that case what will matter is whether the adjustment takes place relatively more along one dimension, as opposed to the other. Ruling out measure zero events-when no adjustment dominates-either one set of predictions or the other holds.
}

Program, both provides new cross-country evidence for the role of welfare-state considerations and reinforces the results in the literature on labor market determinants. In particular, using a direct and indirect measure of the relative skill mix of natives to immigrants, we find evidence that is consistent with the tax adjustment model (according to which it is high-income individuals who are most affected through the welfare-state channel) and with labor market determinants of immigration attitudes. Our results show that, in countries where natives are on average more skilled than immigrants, individual income is negatively correlated with pro-immigration preferences, while individual skill is positively correlated with them. These relationships have the opposite signs in destinations characterized by skilled migration. We confirm the robustness of these results using an alternative data set, the European Social Survey, carried out in 2002-2003 on a different sample of countries.

A growing literature in economics focuses on individual preferences, ${ }^{10}$ as they represent a primary determinant of final policy outcomes (Rodrik, 1995). In this paper we study welfare-state determinants of migration opinions, for two main reasons. First, public-finance issues have played a key role in the historical debate on immigration. However, there are only a few papers in the literature that investigate welfare-state determinants of individual attitudes ${ }^{11}$ and they either focus on a single country or do not exploit the variation in the data across countries. In our analysis, instead, we investigate cross-country heterogeneity in the impact of individual-level variables by taking advantage of the variation in the data at both the individual and the country levels. The second reason for this paper is methodological. In the existing literature, the correlation between individual skill and pro-immigration attitudes is interpreted as evidence in support of a labor market competition story. ${ }^{12}$ For example, in the United States and other countries receiving unskilled migration, the estimated correlation is positive, which is consistent with the labor market hypothesis. However, given that individual skill and income are positively correlated, the same pattern would be observed in the data according to the benefit adjustment model. In other words, it might well be that skilled individuals are less opposed to unskilled immigration because they also enjoy high incomes and do not use public services, relatively speaking, as much as the unskilled. As a result, it is difficult to separate the effect of the two channels on individual attitudes. In general, any other determinant of proimmigration attitudes that is correlated with individual skill

\footnotetext{
${ }^{10}$ See, for example, Luttmer (2001), Alesina and La Ferrara (2005), Blanchflower and Oswald (2004), Caplan (2002), and the literature surveyed below.

${ }^{11}$ See Hanson (2005), Hanson, Scheve, and Slaughter (2005, 2007), and Dustmann and Preston (2004a, 2004b).

${ }^{12}$ See Scheve and Slaughter (2001), Kessler (2001), Mayda (2006), and O'Rourke and Sinnott (2006). See Espenshade and Hempstead (1996) and Hainmueller and Hiscox (2007) for an alternative interpretation of the empirical evidence.
} 
will give rise to a similar problem of omitted variable bias. In order to isolate the labor market channel, previous studies (Scheve \& Slaughter, 2001; Mayda, 2006) compare the correlation between skill and pro-immigration preferences in the labor force versus out of labor force subsamples. Any correlation should disappear for individuals out of the labor force if the labor market is what is driving the result, which is in fact what the previous literature finds. In this paper we tackle the problem in a different way. By explicitly considering welfare-state drivers, our analysis provides a new and more direct approach to differentiate between labor market and public-finance determinants.

The outline of the paper is as follows. Section II surveys the literature related to this paper, while section III presents the two theoretical models. In section IV we describe the data used in the empirical analysis, whose results are presented in section V. Finally, section VI concludes.

\section{Literature}

Our paper is related to different strands of the literature. The first investigates the impact of immigration on the welfare state and has shaped the debate about immigration policy in the United States, Europe, and other destination countries. Borjas and Hilton (1996) and Borjas (1999b), for instance, have extensively documented how immigrant households that have relocated to the United States during the 1980s and 1990s are more likely to receive welfare benefits than the native population. While most of the existing gap in participation rates can be explained by observable characteristics, this is evidence of the growing pressure put on state and federal budgets by "new Americans."13 Looking at a large sample of E.U. countries, Boeri, Hanson, and McCormick (2002) point out instead a substantial dispersion in the immigrants' participation in the welfare state. Furthermore the paper shows that, while immigrants are on average more likely than natives to be on the receiving end of unemployment and family benefits, this turns out not to be the case for old age pension benefits. ${ }^{14}$ Finally, Razin, Sadka, and Swagel (2002) analyze the extent to which, in the long run, immigration affects the redistribution carried out by the welfare state. In a very elegant theoretical model the paper shows how-somewhat surprisingly - the presence of a fiscal leakage from the native to

\footnotetext{
${ }^{13}$ For an analysis of the long-run effects of immigration on the welfare state in the United States, see also Smith and Edmonston (1997).

${ }^{14}$ See Boeri, Hanson, and McCormick (2002), table 3.2, p. 747. This argument has been used by many policymakers in Europe to highlight the potential role of immigration policy as a tool to deal with the difficulties created by pay as you go social security systems in the presence of an aging population. For a formal analysis, see Razin and Sadka (1999), while Storesletten (2000) has studied how migration policy can be used to sustain the existing welfare system in the United States. See also Haup and Peters (2003). Casarico and Devillanova (2003) consider the two adjustment models in the analysis of the impact of immigration on the social security system.
}

the foreign-born population is likely to play against redistribution toward the less skilled. ${ }^{15}$

The second set of papers related to our work looks, more specifically, at how welfare-state considerations affect individual perceptions of immigration. Hanson, Scheve, and Slaughter (2007) investigate the impact of both publicfinance and labor market variables on individual preferences over globalization-migration and trade-in the United States in 1992 and 2000. The empirical analysis shows that, while the pre-tax cleavages in individual attitudes-working through the labor market channel-are similar for immigration and trade, the post-tax cleavages in opinionsworking through the public-finance channel are different. The authors conclude that welfare-state considerations are therefore important in explaining differences in individual attitudes toward alternative globalization strategies. Hanson, Scheve, and Slaughter (2007) is the paper in the literature closest to ours. From a theoretical point of view, Hanson, Scheve, and Slaughter's (2007) analysis differs from our work in that the authors do not consider the two public-finance models we instead analyze, implicitly assuming that the first one holds. ${ }^{16}$ From an empirical point of view, while their paper focuses on the United States and exploits the across-state variation in the data, our analysis is a cross-country one. In addition, the main innovation of our empirical analysis relative to Hanson, Scheve, and Slaughter (2007) is to incorporate data on the relative skill mix of natives to immigrants, which varies considerably across countries and affects whether immigrants represent a net burden or benefit for the welfare state. ${ }^{17}$ The role of the welfare-state channel in explaining attitudes toward immigration is also highlighted in Hanson (2005), where a "rights-based" immigration policy is proposed to limit the burden put by unskilled immigrants on the welfare state. ${ }^{18}$

Dustmann and Preston (2004b) empirically analyze attitudes toward immigrants in Great Britain using seven consecutive waves of an individual-level panel data set, the British Social Attitudes Survey. The authors develop a structural multiple-factor model that uses responses to various questions on racial, labor market, and welfare issues to estimate the direct impact of the underlying three factors on

\footnotetext{
${ }^{15}$ The intuition for this result is that, as the number of migrants grows, a larger proportion of the fiscal revenues ends up in the hands of unskilled immigrants, which implies that native taxpayers-among whom the median voter will most likely be counted-will opt for lower taxes.

${ }^{16}$ Hanson, Scheve, and Slaughter's (2007) empirical work makes it possible to distinguish between the two mechanisms. The results in this paper are consistent with what we call the tax adjustment model. However, this paper does not explicitly address the distinction between the two scenarios.

${ }^{17}$ Hanson, Scheve, and Slaughter (2005) use across-state variation in the skill composition of immigrants to the United States. This paper estimates the impact of the latter variable on skill cleavages in U.S. immigration opinions, but not separately for the labor market versus welfare-state channels.

18 The basic idea is to differentiate the level of entitlement to public benefits, depending on how long the immigrants have been in the host country. The immediate effect of this policy would be a reduction in the benefits available to immigrants through the welfare state.
} 
immigration attitudes. Using a similar structural multiplefactor model on data from the 2002-2003 wave of the European Social Survey, Dustmann and Preston (2004a) focus on economic variables and analyze three alternative channels through which individual attitudes toward immigrants are affected: labor market competition, public burden, and efficiency considerations. Besides the methodological approach, these two works differ from our paper since the analysis focuses on a single country (Dustmann \& Preston, 2004b) or does not explore the cross-country heterogeneity in the effect of individual-level variables (Dustmann \& Preston, 2004a). In addition, the welfare state is implicitly assumed to adjust to immigration through changes in tax levels.

Finally, our paper is also related to analyses of immigration preferences that focus on the labor market competition hypothesis. Using data on the United States, both Scheve and Slaughter (2001) and Kessler (2001) find that more educated individuals are more likely to be pro-immigration, which is consistent with a labor market story, as immigrants to the United States are less skilled than natives on average. Mayda (2006) and O'Rourke and Sinnott (2006) extend the analysis to a multicountry framework. Both papers find that a key variable determining the sign of country-specific correlations, between individual skill and attitudes, is the relative skill composition of natives to immigrants. Using both direct and indirect measures of this variable, individual skill is estimated to be positively (negatively) correlated with pro-immigration preferences if migrants are unskilled (skilled). Our paper finds the same results but in a broader framework, where the labor market interacts with the welfare state.

\section{Theoretical Framework}

To analyze the effect of immigration on individual attitudes we consider a simple two-factor HO model of a small open economy ${ }^{19}$ with and without diversification in production, and we augment it by incorporating a redistributive welfare system, like in Dustmann and Preston (2004a). ${ }^{20}$ If production is diversified, two goods are produced. Alternatively, if the economy is not diversified, only one good is produced. We can think of the two production factors as unskilled $\left(L_{U}\right)$ and skilled labor $\left(L_{S}\right)$. They are combined using a constant returns to scale technology $y_{i}=f_{i}\left(L_{U}, L_{S}\right)$ to produce output $i \in 1,2$. We will assume good 1 to be the numeraire, so that its price will be normalized to 1 , while $p$ will be the price of good 2. The economy is populated by a set of $N$ natives, indexed by $n$, and by a set of $M$ immigrants, indexed by $m$. Each native is endowed with one unit of labor

\footnotetext{
${ }^{19}$ Thus, since a small open economy without nontradable sectors takes international prices as given, we abstract from the potential price effects of immigration.

${ }^{20}$ The main difference between our framework and theirs is that, while we allow the welfare state to adjust to migration in two different ways, they assume the adjustment to occur only through changes in tax rates.
}

(either skilled or unskilled) and with an amount $e^{n} \in\left\{e^{L}\right.$, $\left.e^{H}\right\}$ of the numeraire good, where $e^{H}>e^{L}$. As a result, we can distinguish four different types of natives, based on their skill levels and asset holdings. ${ }^{21}$ Immigrants are only endowed with either one unit of skilled or unskilled labor. ${ }^{22}$ The total endowment of the numeraire good in the economy is thus given by

$$
\sum_{n} e^{n}=E,
$$

while the total supply of each skill is given by

$$
L_{j}=\phi_{j} N+\psi_{j} M, j \in\{U, S\},
$$

where $\phi_{j}$ and $\psi_{j}$ are, respectively, the share of workers of skill profile $j$ in the native and immigrant populations, and $\Sigma_{j} \phi_{j}=\Sigma_{j} \psi_{j}=1$. The key variable in our analysis of the effect of immigration is the migrants to natives ratio, which is defined as $\pi=M / N$ and which, for simplicity, we will assume to be equal to 0 in the initial equilibrium. Furthermore, the number of natives will be held constant throughout the analysis. A change in the immigrants to natives ratio will impact the domestic availability of the two types of skills in the following way:

$$
\frac{\hat{L}_{j}}{d \pi}=\frac{\psi_{j}}{\phi_{j}}=\beta_{j}
$$

where $\hat{L}_{j}=\frac{d L_{j}}{L_{j}}$ and so on. Let $w_{j}$ be the (before tax) prevailing wage rate, with $w_{S}>w_{U}$. Let $c_{i}\left(w_{U}, w_{S}\right)$ be the unit cost function for good $i$. Wages and outputs are determined by two sets of equilibrium conditions. Firstly, equilibrium in the factor market requires supply to be equal to demand,

$$
\begin{aligned}
& L_{U}=y_{1} \frac{\partial c_{1}\left(w_{U}, w_{S}\right)}{\partial w_{U}}+y_{2} \frac{\partial c_{2}\left(w_{U}, w_{S}\right)}{\partial w_{U}}, \\
& L_{S}=y_{1} \frac{\partial c_{1}\left(w_{U}, w_{S}\right)}{\partial w_{S}}+y_{2} \frac{\partial c_{2}\left(w_{U}, w_{S}\right)}{\partial w_{S}} .
\end{aligned}
$$

Secondly, perfect competition implies that firms earn nonpositive profits in equilibrium, that is,

$$
\begin{aligned}
& 1 \leq c_{1}\left(w_{U}, w_{S}\right), \\
& p \leq c_{2}\left(w_{U}, w_{S}\right) .
\end{aligned}
$$

\footnotetext{
${ }^{21}$ As skilled individuals with a limited initial endowment could well be poorer than low-skilled individuals with abundant assets, we allow for individual skill and income to be not perfectly correlated, and we will exploit this differential variation in the empirical analysis.

${ }^{22} \mathrm{We}$ make this assumption, following Razin, Sadka, and Swagel (2002), to highlight the possibility of a welfare leakage effect from natives to migrants.
} 
Assume that the government intends to levy an egalitarian income tax consisting of a flat rate $\tau$, accompanied by a lump sum rebate $b .^{23}$ The cash grant may be thought of as capturing the provision of free public services, and for simplicity we are assuming that migrants are entitled to all public programs available in the destination country. Thus, by design, our tax system is redistributive. The government budget constraint can be written as

$$
\tau\left(w_{U} L_{U}+w_{S} L_{S}+E\right)=b(N+M) .
$$

Immigration affects the well-being of the current residents through three possible channels: tax rates, per capita transfers, ${ }^{24}$ and labor market. The net income of a native $n$ of skill level $j$ is given by

$$
I_{j}^{n}=(1-\tau) G_{j}^{n}+b,
$$

where $G_{j}^{n}=w_{j}+e^{n}$. The effect of immigration on her net income can then be measured by

$$
\frac{\hat{I}_{j}^{n}}{d \pi}=\frac{(1-\tau) w_{j} \frac{\hat{w}_{j}}{d \pi}}{I_{j}^{n}}-\frac{\tau G_{j}^{n} \frac{\hat{\tau}}{d \pi}}{I_{j}^{n}}+\frac{b \frac{\hat{b}}{d \pi}}{I_{j}^{n}} .
$$

The first term represents the labor market effect, the second is the effect through the adjustment in the tax level, and the third term represents the adjustment induced in the government's transfers to the residents. We will now consider the effect of immigration on the utility of current residents under two different hypotheses. First, we will assume that factor returns are not affected by immigration, and will call this the "no labor market effect scenario." Next we will study the effect of immigration when a change in endowments changes instead factor returns.

\section{A. No Labor Market Effect}

To gain some intuition on the importance of the type of welfare-state response to immigration in shaping individual attitudes, we consider a simplified setting in which one of two adjustments can occur. In the first, which we label the tax adjustment model, per capita transfers are held constant, and the tax rate reacts to maintain the government's budget in equilibrium. In the second, which we call the benefit adjustment model, tax rates do not change, while the per capita transfers adjust. We start by analyzing the tax adjust-

\footnotetext{
${ }^{23}$ The literature has suggested (Mirrlees, 1971) that the best egalitarian income tax can be approximated by a linear tax. This strategy has been followed for instance by Razin, Sadka, and Swagel (2002), among others.

${ }^{24}$ The first two channels work through the welfare state. In our model, we assume that the government's budget constraint must be satisfied in each year. In practice, immigration might also affect the welfare state through its impact on the accumulation of public debt. While explicitly modeling this channel would render the analysis more complicated, allowing for the accumulation of debt would only shift into the future the choice between changing taxes or benefits to accommodate immigration.
}

ment model. Totally differentiating equation (7), after a few manipulations we obtain

$$
\hat{\tau}+\sum_{j} \eta_{j} \hat{L}_{j}=d \pi
$$

where $\eta_{j}=\frac{w_{j} L_{j}}{\sum_{i} w_{i}+E}$ for $j=U, S$ is the share of labor of skill level $j$ in total domestic income, and $\eta_{E}=1-\eta_{U}-\eta_{S}$ is the share of the initial endowment in total domestic income. The effect of immigration on the tax rate is given by

$$
\frac{\hat{\tau}}{d \pi}=\frac{\left(\phi_{U}-\eta_{U}\right)\left(\beta_{U}-1\right)}{\left(1-\phi_{U}\right)}+\frac{\eta_{E}\left(1-\psi_{U}\right)}{1-\phi_{U}},
$$

where $\phi_{U}-\eta_{U}$ is the difference between the share of the unskilled in the initial population and their share in the initial GDP. Since $w_{U}<w_{S}$, it follows immediately that $\phi_{U}>\eta_{U}$. Consider equation (11) and to begin with, assume that the share of initial endowment in national income is nil, in other words, that $\eta_{E}=0$. If the native and migrant skill compositions are identical, that is, if $\beta_{U}=1$, an inflow of immigrants will not alter the current tax level. If instead immigrants are less skilled on average than natives, that is, if $\beta_{U}>1$, their presence will lead to an increase in the tax rate. This is intuitive since, in order to maintain the same per capita transfer, a reduction in the per capita pre-tax income will require an increase in the tax rate. If the share of the initial endowment in national income is instead positive, that is, $\eta_{E}>$ 0 , the increase in the tax rate needed to maintain a given demogrant in the presence of unskilled immigration will be even higher. As immigrants in our model are assumed not to own other assets besides labor, even if they are as skilled as natives (that is, $\beta_{U}=1$ ), they represent a net burden for the welfare state and this will require an increase in the tax rate to maintain the demogrant unchanged. ${ }^{25}$ The following proposition then holds.

Proposition 1 (tax adjustment model). Holding the demogrant unchanged, an inflow of unskilled immigrants is less desirable for an individual the higher her pre-tax income. To the contrary, an inflow of skilled immigrants is more desirable for an individual the higher her pre-tax income as long as $\eta_{E}<\eta_{E}^{*}$, where $\eta_{E}^{*}=\frac{\left(1-\beta_{U}\right)\left(\phi_{U}-\eta_{U}\right)}{\left(1-\psi_{U}\right)}$.

Proof. See appendix.

\footnotetext{
${ }^{25}$ A similar "fiscal leakage" effect has been modeled by Razin, Sadka and Swagel (2002). Notice also that, the more unskilled immigrants are, the higher the tax increase required to maintain the demogrant unchanged. To see this, notice that $\frac{\partial\left(\frac{\hat{f}}{d \pi}\right)}{\partial \psi_{U}}=\frac{\phi_{U}\left(1-\eta_{E}\right)-\eta_{U}}{\phi_{U}\left(1-\phi_{U}\right)}>0$ since $\phi_{U}>\frac{\eta_{U}}{\eta_{U}+\eta_{s}}$.
} 
Proposition 1 tells us that, if the demogrant is held fixed, the redistributive nature of the existing fiscal system implies that the cost of an inflow of unskilled immigrants will fall disproportionately more on higher-income natives. Similarly, if immigration is skilled in nature, the higher-income natives will be the largest beneficiaries since they will enjoy a disproportionately large decrease in their net tax burden. To see how the relationship is affected by a change in the extent of redistribution carried out by the welfare state, we need to calculate the following derivative:

$$
\frac{d\left(\frac{\partial\left(\frac{1}{d \pi}\right)}{\partial G}\right)}{d \tau}=-\frac{\hat{\tau}}{d \pi} \frac{2 b G}{[b+G(1-\tau)]^{3}},
$$

which is negative as long as immigration is unskilled since $\frac{\hat{f}}{d \pi} \geq 0$. In other words, the negative relationship between individual income and pro-immigration preferences (according to the tax adjustment model and given unskilled migration) becomes more pronounced the more redistributive the welfare system is.

We turn now to the benefit adjustment model, in which tax rates are held fixed, and the government's budget is kept in equilibrium by changes in the demogrant. Totally differentiating equation (7), we have

$$
\frac{\hat{b}}{d \pi}=\frac{\left(\phi_{U}-\eta_{U}\right)\left(1-\beta_{U}\right)}{1-\phi_{U}}-\frac{\eta_{E}\left(1-\psi_{U}\right)}{\left(1-\phi_{U}\right)} .
$$

Also in this case, if $\eta_{E}=0$ and $\beta_{U}=1$, migration will have no effect on the demogrant. On the other hand, since $\phi_{U}>\eta_{U}$, unskilled immigration (that is, $\beta_{U}>1$ ) will lead to a decline in the per capita transfers, ${ }^{26}$ while skilled immigration $\left(\beta_{U}<1\right)$ will lead to an increase. If $\eta_{E}>0$, the reduction in the demogrant that follows from an inflow of unskilled immigrants will be even larger. In fact a positive share of initial endowment in national income implies that natives are richer, ceteris paribus, than the immigrants in the initial equilibrium. As a result, the effect of unskilled immigration on the demogrant, holding the tax fixed, will be more pronounced.

The following result characterizes the effect of immigration on the current residents.

Proposition 2 (benefit adjustment model). Holding the tax rates fixed, an inflow of unskilled immigrants is less desirable for an individual the lower her pre-tax income. To the contrary, an inflow of skilled immigrants is more desirable for an individual the lower her pre-tax income as long as $\eta_{E}<\eta_{E}^{*}$, where $\eta_{E}^{*}=\frac{\left(1-\beta_{v}\right)\left(\phi_{\psi}-\eta_{v}\right)}{\left(1-\psi_{v}\right)}$.

\footnotetext{
${ }^{26}$ Furthermore, as is intuitive, the more unskilled immigrants are, the larger will be the reduction in the demogrant. To see this, notice that $\frac{\partial\left(\frac{\hat{b}}{d \pi}\right)}{\partial \psi_{U}}=\frac{\eta_{U}-\phi_{U}\left(\eta_{S}+\eta_{U}\right)}{\phi_{U}\left(1-\phi_{U}\right)}<0$ since $\frac{\eta_{U}}{\phi_{U}}<\frac{\eta_{S}}{\phi_{S}}$.
}

Proof. See appendix.

The result in proposition 2 is fairly general and the intuition is straightforward. The inflow of unskilled immigrants will-for a given tax rate-reduce the demogrant paid to every native. The reduction in the demogrant will have a larger impact on the individuals with a smaller income. The opposite is true-that is, the increase in the demogrant will have a more positive impact on low-income individuals - if immigration is instead skilled, and the share of the initial endowment in national income is small. To see how the relationship is affected by a change in the redistribution carried out by the welfare state, we need to calculate the following derivative:

$$
\frac{d\left(\frac{\partial\left(\frac{1}{d \pi}\right)}{\partial G}\right)}{d b}=-\frac{\hat{b}[G(1-\tau)-b]}{d \pi[b+G(1-\tau)]^{3}},
$$

which is positive if migration is unskilled as long as $G(1-$ $\tau)>b$.

\section{B. With Labor Market Effects}

We turn now to the second setting, in which the economy is initially specialized in the production of only good 1 . Factor returns are then determined by the following set of equations:

$$
\begin{aligned}
& 1=c_{1}\left(w_{U}, w_{S}\right), \\
& L_{U}=y_{1} \frac{\partial c_{1}\left(w_{U}, w_{S}\right)}{\partial w_{U}}, \\
& L_{S}=y_{1} \frac{\partial c_{1}\left(w_{U}, w_{S}\right)}{\partial w_{S}} .
\end{aligned}
$$

Totally differentiating the equilibrium conditions, it is easy to show that the effect of immigration on wages is given by

$$
\begin{aligned}
& \frac{\hat{w}_{U}}{d \pi}=\frac{\beta_{U}-\beta_{S}}{\varepsilon_{U U}-\left(\varepsilon_{S U}+\frac{\eta_{U}}{\eta_{s}} \varepsilon_{U S}\right)+\frac{\eta_{U}}{\eta_{s}} \varepsilon_{S S}}, \\
& \frac{\hat{w}_{S}}{d \pi}=-\frac{\eta_{U}}{\eta_{S}} \frac{\beta_{U}-\beta_{S}}{\varepsilon_{U U}-\left(\varepsilon_{S U}+\frac{\eta_{U}}{\eta_{s}} \varepsilon_{U S}\right)+\frac{\eta_{U}}{\eta_{s}} \varepsilon_{S S}},
\end{aligned}
$$

where $\varepsilon_{i j}=\frac{\partial L_{i}}{\partial w_{j}} \frac{w_{j}}{L_{i}}$. From these two equations, we immediately see that only if immigrants share exactly the same skill composition as natives, there will be no wage effects. If the skill composition of immigrants is different from that of the natives, then there will be wage effects. In particular, an inflow of unskilled immigrants will lead to a reduction of 
the wage of domestic unskilled workers, while the opposite will hold for skilled workers. ${ }^{27}$

Turning back to the effect of immigration on the welfare state when wages adjust, holding the demogrant unchanged (tax adjustment model) the impact on the tax rates of skilled and unskilled immigration can be rewritten as

$$
\frac{\hat{\tau}}{d \pi}=\frac{\left(\phi_{U}-\eta_{U}\right)\left(\beta_{U}-1\right)}{\left(1-\phi_{U}\right)}+\frac{\eta_{E}\left(1-\psi_{U}\right)}{1-\phi_{U}}-\sum_{j} \eta_{j} \frac{\hat{w}_{j}}{d \pi} .
$$

On the other hand, holding the tax rates constant and allowing the demogrant to adjust (benefit adjustment model), the impact of immigration on the demogrant becomes

$$
\frac{\hat{b}}{d \pi}=\frac{\left(\phi_{U}-\eta_{U}\right)\left(1-\beta_{U}\right)}{1-\phi_{U}}-\frac{\eta_{E}\left(1-\psi_{U}\right)}{1-\phi_{U}}+\sum_{j} \eta_{j} \frac{\hat{w}_{j}}{d \pi} .
$$

In both situations, we can see that now the effects on the two dimensions of the welfare state will be mediated by the labor market. At the margin, labor is paid the value of its marginal product, so a marginal inflow of immigrants will leave the total remuneration of the existing labor force unchanged $\left(\Sigma_{j} \eta_{j} \frac{w_{j}}{d \pi}=0\right)$ and have no effect on the redistribution carried out by the welfare state. On the other hand, if the inflow of immigrants is nonmarginal (that is, $\Delta \pi$ ), the total remuneration of existing workers will rise $\left(\Sigma_{j} \eta_{j} \frac{\hat{w}_{j}}{\Delta \pi} \geq\right.$ $0)^{28}$ and relax the government's budget constraint. ${ }^{29}$

\footnotetext{
${ }^{27}$ This result follows from the concavity of the cost function, which implies that the sign of the denominator of equations (18) and (19) is negative. See Dustmann and Preston (2004a) for a proof.

${ }^{28}$ These are the gains from migration pointed out by Berry and Soligo (1969) and Borjas (1995).

${ }^{29}$ In the theoretical model, we have considered three economic channels, that is, the welfare-state channel, the labor market channel, and the efficiency channel. The assumptions in the model (small open economy, the absence of a nontradable sector, and homothetic and identical preferences across individuals) imply that we abstract from the price channel. That is, migration does not have a differential impact on various income groups through price changes. In a more general model, immigration could have effects on commodity prices-for example, in the presence of a nontradable sector and/or individuals belonging to different income groups might be characterized by different consumption baskets. Thus, in a general setup, heterogeneous individuals might have different preferences over immigration because of price effects. The only empirical paper we have found on these issues is Cortes (2006), which uses highly disaggregated U.S. data at the city level. She finds that immigration affects the prices of nontraded goods and services; however, her evidence suggests that the effect of immigration on the cost of living indexes does not differ substantially across income groups. In particular, across U.S. cities the average decrease in the cost of living due to immigration in the 1990s is very similar for high school dropouts, high school graduates, and college graduates $(0.92 \%, 0.94 \%$, and $0.96 \%$, respectively; see table 14 in the appendix of her paper).
}

\section{Data}

To empirically investigate these theoretical predictions, we combine individual-level information on immigration attitudes with aggregate data on the characteristics of destination countries. In particular, we use survey results from the 1995 National Identity Module of the International Social Survey Programme (ISSP), which covers advanced, middle-income, and developing economies. We restrict the sample and only focus on higher-income countries, which are the best suited for the analysis of welfare-state determinants. First, the salience of migration issues is lower in countries with few immigrants and these tend to be countries with lower income, which are the ones we exclude from our sample. In addition, our sample selection excludes poorer countries in Eastern Europe which were in 1995 in the early stages of the economic transition and for which a Western-style welfare state was just beginning to emerge (see for instance Campos \& Coricelli, 2002)..$^{30}$

To construct a measure of immigration attitudes, we use respondents' answers in the ISSP survey to the following question: "There are different opinions about immigrants from other countries living in (respondent's country). By "immigrants' we mean people who come to settle in (respondent's country). Do you think the number of immigrants to (respondent's country) nowadays should be: (a) reduced a lot, (b) reduced a little, (c) remain the same as it is, (d) increased a little, or (e) increased a lot." The survey format also allows for "can't choose" and "not available" responses, which we exclude from the sample. We also leave out observations for individuals who are not citizens of the country where they are interviewed. The dependent variable in our empirical analysis, pro-immig dummy, is dichotomous and equal to 1 for respondents who would like the number of immigrants to increase (either a little or a lot) and equal to 0 otherwise. ${ }^{31}$ Our empirical analysis is based on estimation of probit models (the tables report coefficient estimates). All specifications have robust standard errors adjusted for clustering on country, ${ }^{32}$ to address heteroskedasticity and allow for correlation across individual observations within the same country, and include destination

\footnotetext{
${ }^{30}$ In particular, our sample includes countries with per capita GDP (PPP-adjusted) in 1995 above 8,000 international dollars: Austria, Canada, Czech Republic, East Germany, Great Britain, Hungary, Ireland, Italy, Japan, Netherlands, New Zealand, Norway, Slovak Republic, Slovenia, Spain, Sweden, United States, West Germany. Italy is excluded from regressions that use real income, as this variable is not available.

${ }^{31}$ We have checked the robustness of our results to various alternatives with respect to how the dependent variable is constructed (for example, keeping the "can't choose" and "not available" observations; defining the middle category (c) as pro-immigration; using as dependent variable a five-valued ordered measure; and so on).

32 There is no consensus in the literature regarding whether standard errors should be simply "robust" or also "clustered by country." Therefore, we also run the regressions with standard errors set to be robust and find very similar results.
} 
TABle 1.-Summary Statistics of Individual-LeVEl VARIABles (ISSP Data Set)

\begin{tabular}{|c|c|c|c|c|c|}
\hline Variable & Obs & Mean & Std. Dev. & Min & Max \\
\hline Pro-immig dummy & 13,605 & 0.0786 & 0.2691 & 0.0000 & 1.0000 \\
\hline Pro-trade dummy & 7,966 & 0.2797 & 0.4489 & 0.0000 & 1.0000 \\
\hline Age & 13,605 & 44.7291 & 16.0457 & 14.0000 & 96.0000 \\
\hline Male & 13,605 & 0.5048 & 0.5000 & 0.0000 & 1.0000 \\
\hline Log of real income & 13,605 & 9.1908 & 1.2025 & 3.9616 & 11.6643 \\
\hline Education (years of education) & 13,605 & 12.0949 & 3.4868 & 1.0000 & 20.0000 \\
\hline Pro-immig crime & 13,605 & 0.2711 & 0.4445 & 0.0000 & 1.0000 \\
\hline Pro-immig culture & 13,605 & 0.5130 & 0.4999 & 0.0000 & 1.0000 \\
\hline Upper social class & 6,364 & 3.4239 & 1.0982 & 1.0000 & 6.0000 \\
\hline Trade union member & 6,364 & 0.4419 & 0.4966 & 0.0000 & 1.0000 \\
\hline Political affiliation with the right & 6,364 & 2.8914 & 0.9559 & 1.0000 & 5.0000 \\
\hline
\end{tabular}

Pro-immig dummy is based on responses to the following question: "Do you think the number of immigrants to (respondent's country) nowadays should be reduced a lot (1), reduced a little (2), remain the same as it is (3), increased a little (4), increased a lot (5); can't choose; NA." Pro-immig dummy = 1 if answers to the above question are either (4) or (5); 0 if they are either (1), (2), or (3). Can't choose and NA are treated as missing values.

Pro-trade duminy is based

is based on responses to the following question: "Now we would like to ask a few questions about relations between (respondent's country) and other countries. How much do you agree or disagree with the following statements: (respondent's country) should limit the import of foreign products in order to protect its national economy: 1 = agree strongly; 5 = disagree strongly; can't choose; NA." Pro-trade dummy $=1$ if answers to the above question are either (4) or (5); 0 if they are either (1), (2), or (3). Can't choose and NA are treated as missing values.

Male is coded as follows: 1 male, 0 female (i.e., missing values are excluded). Log of real income is calculated using data in local currency on individual yearly income from the ISSP-NI data set and purchasing-power-parity conversion factors from the WDI (World Bank). Upper social class is coded as follows: $1=$ lower, $2=$ working, $3=$ lower middle, $4=$ middle, $5=$ upper middle, $6=$ upper. Trade union member equals 1 if the individual is a member of a trade union, 0 if he is not. Political affiliation with the right is coded as follows: $1=$ far left, $2=$ center left, $3=$ center, $4=$ right, $5=$ far right.

Pro-immig crime is based on responses to the following question: "How much do you agree or disagree with the following statement? Immigrants increase crime rates: $1=$ agree strongly; $5=$ disagree strongly." Pro-immig crime $=1$ if answers to the above question are either (4) or (5); 0 otherwise. Pro-immig culture is based on responses to the following question: "How much do you agree or disagree with the following statement? Immigrants make (respondent's country) more open to new ideas and cultures: 1 = disagree strongly; 5 = agree strongly." Pro-immig culture $=1$ if answers to the above question are either (4) or (5); 0 otherwise.

Summary statistics for pro-immig dummy, age, male, log of real income, education, pro-immig crime, and pro-immig culture are based on the same observations as in regressions 1-3 and 5-7 in table 5.

Summary statistics for pro-trade dummy are based on the same observations as regression 6 in table 7.

Summary statistics for upper social class, trade union member, and political affiliation with the right are based on the same observations as regression 4 in table 5 .

Table 2.-Summary Statistics of Individual-Level Variables by Country (ISSP Data Set) and of Country-Level Variables

\begin{tabular}{|c|c|c|c|c|c|c|c|c|c|}
\hline Country & $\begin{array}{l}\text { Pro-Immig } \\
\text { Dummy }\end{array}$ & $\begin{array}{l}\text { Pro-Trade } \\
\text { Dummy }\end{array}$ & Education & $\begin{array}{l}\text { Log of Real } \\
\text { Income }\end{array}$ & $\begin{array}{l}\text { Per Capita } \\
\text { GDP }\end{array}$ & $\begin{array}{l}\text { Relative Skill } \\
\text { Composition }\end{array}$ & Benefits & Progressivity & $\begin{array}{c}\text { Labor Tax } \\
\text { Rate }\end{array}$ \\
\hline United States & 0.0805 & 0.1326 & 13.4257 & 9.6637 & 27,395 & & 3,350 & 8.0000 & 29.1050 \\
\hline Norway & 0.0743 & 0.2920 & 12.6633 & 9.6180 & 24,694 & & 5,374 & 11.3000 & 40.6000 \\
\hline Japan & 0.1568 & 0.3600 & 11.8682 & 9.6473 & 23,212 & & 7,645 & 5.8000 & 29.3630 \\
\hline Canada & 0.2061 & 0.2855 & 14.7612 & 9.9558 & 23,085 & 1.6709 & 2,433 & 11.9000 & 30.3440 \\
\hline Austria & 0.0395 & 0.1679 & 10.3555 & 9.2601 & 22,090 & 2.5329 & 6,181 & 10.4000 & 39.6070 \\
\hline Germany West & 0.0282 & 0.3854 & 10.9086 & 9.4788 & 21,479 & 4.0923 & 4,438 & 12.9000 & 40.2100 \\
\hline Germany East & 0.0199 & 0.2312 & 10.9497 & 9.1904 & 21,479 & 4.0923 & 4,438 & 12.9000 & 40.2100 \\
\hline Netherlands & 0.0547 & 0.3930 & 12.6851 & 9.9000 & 20,812 & 2.6941 & 7,166 & 15.9000 & 49.7960 \\
\hline Italy & 0.0355 & 0.2315 & 11.0284 & & 20,513 & 0.6374 & 3,475 & 8.8000 & 42.1830 \\
\hline Sweden & 0.0671 & 0.2468 & 11.4111 & 9.5651 & 20,031 & 1.3362 & 5,879 & 11.0000 & 53.0110 \\
\hline Great Britain & 0.0413 & 0.1433 & 11.3209 & 9.8841 & 19,465 & 2.2523 & 2,163 & 6.0000 & 24.5040 \\
\hline New Zealand & 0.1159 & 0.2513 & 14.3098 & 9.5682 & 17,706 & & 2,705 & 5.8000 & 24.9920 \\
\hline Ireland & 0.1910 & 0.2260 & 12.2490 & 9.1528 & 17,264 & 0.3950 & 2,370 & 15.5000 & \\
\hline Spain & 0.0844 & 0.1107 & 10.1275 & 9.0672 & 15,163 & 0.4668 & 1,899 & 10.0000 & 36.9000 \\
\hline Slovenia & 0.0186 & 0.2619 & 10.6766 & 8.7888 & 12,978 & & & & \\
\hline Czech Republic & 0.0244 & 0.2778 & 12.9111 & 8.6610 & 12,426 & & & 4.9000 & \\
\hline Hungary & 0.0148 & 0.0992 & 10.4914 & 8.1421 & 9,315 & & & 16.9000 & \\
\hline Slovak Republic & 0.0302 & 0.2566 & 11.8364 & 5.9451 & 8,487 & & & & \\
\hline
\end{tabular}

Per capita GDP is for 1995, PPP (current international dollars). The relative skill composition (RSC) is the ratio of skilled to unskilled labor in the native relative to the immigrant populations. For both natives and immigrants, the ratio of skilled to unskilled labor is measured as the ratio of the number of individuals with levels 2 and 3 of education to the number of individuals with level 1 of education. The RSC uses data on the stock of immigrants and natives in 1995. Benefits is per capita transfers in 1995. Progressivity is equal to the difference in average income tax rates applied to single individuals without children who earn, respectively, $167 \%$ and $67 \%$ of the annual wage earnings of an average production worker (OECD, 1998). Labor tax rate is the 1990 labor tax rate. See table 1 footnote for definitions of pro-immig dummy, pro-trade dummy, education, and log of real income.

countries' fixed effects, ${ }^{33}$ to account for the impact of unobserved, additive, country-specific effects. These intercepts make it possible to net out the impact of country-level variables which is homogeneous across fellow citizens (for

${ }^{33}$ Fixed-effect estimation of a probit model may give rise to the so-called incidental parameter problem (Chamberlain, 1984): the maximum likelihood estimator of the incidental parameters (fixed effects) is consistent as $T \rightarrow \infty$, for given $N$ (assuming that there are $T$ observations for each unit $i=1, \ldots, N)$. However, it is inconsistent for given $T$, as $N \rightarrow \infty$. Given that the panel data set we use is very long ( $N$ small, $T$ high, since there are many individual observations for each country), the incidental parameters problem is not an issue in our case. example, the linear effect of migration policy, of the state of the economy, or of the skill composition of natives relative to immigrants). ${ }^{34}$

Summary statistics for pro-immig dummy and all the other ISSP and country-level variables used in the empirical analysis are presented in tables 1 and 2 . The fraction of individuals in the overall sample who are in favor of

${ }^{34}$ Therefore, these country-level variables cannot be included in the estimating equations (unless interacted with individual-level regressors); otherwise they would be perfectly collinear with the country dummy variables. 
immigration is low (7.9\%). However, this fraction hides substantial cross-country variation. In Canada and Ireland, respondents are the most pro-immigration, in Hungary the least. In contrast, attitudes are much more favorable toward an alternative dimension of globalization, international trade. In the overall sample, $28 \%$ of individuals welcome free trade, with the highest fraction being in the Netherlands and the lowest one in Hungary.

Additional immigration questions are included in the ISSP survey. For example, individuals are asked whether they agree with the statement that immigration increases crime rates and whether they think that immigration makes the country more open to new ideas and cultures. We use answers to these questions to construct two variables, proimmig crime and pro-immig culture, which capture each individual's perception of the security and cultural impact of immigration, respectively. In some specifications we control for these two regressors which measure two important aspects of the perceived noneconomic impact of migration. By comparing two individuals who feel the same in terms of these dimensions, we are better able to isolate the economic channels. At the same time, when we include pro-immig crime and pro-immig culture, we might be underestimating the effect of economic variables, because of the possible endogeneity of the two variables: that is, an individual might be against immigration for economic reasons and, as a consequence, express anti-immigration views from a crime or a cultural point of view.

The ISSP data set also includes information on a number of individual-level characteristics that define the socioeconomic background of each respondent (for example, the age, gender, number of years of education, real income, social class, political affiliation, and trade union membership of the person interviewed). The two variables of interest for our analysis are the individual's number of years of education and real income. We use data on the former to construct a measure of individual skill (education) and test the labor market predictions of the model. We employ data on individual real income to test instead the predictions on welfare-state determinants. In particular, the variable income is calculated using data from the ISSP data set on individual yearly income in local currency and purchasingpower-parity conversion factors from the World Development Indicators (World Bank). ${ }^{35}$

The theoretical predictions about the impact of immigration on natives' preferences, through both the welfare-state and the labor market channels, are different (indeed opposite) depending on the skill composition of natives relative to immigrants in the destination country. Following Mayda (2006), we use two alternative measures of such skill mix. While the first one is a direct measure, it can only be constructed for a limited number of countries, for which the following data are available. We use information on 1995

\footnotetext{
${ }^{35}$ See the footnote of table 1 for definitions of variables based on the ISSP questions.
}

education levels of both native and immigrant populations, which comes from the International Migration Statistics data set for OECD countries (OECD, 1997). Education levels are coded according to the International Standard Classification of Education (ISCED): (i) less than first stage of second level (ISCED 00, 01, 02); ${ }^{36}$ (ii) completed second stage of second level (ISCED 03, 04); (iii) completed third level (ISCED 05 and over); (iv) other general education, not applicable, and no answer. The relative skill composition of natives to immigrants is defined as the ratio of skilled to unskilled labor in the native relative to the immigrant populations. We measure the ratio of skilled to unskilled labor, for both natives and immigrants, as the number of individuals with education levels 2 and 3 divided by the number of individuals with education level 1. In particular, the variable we use in the regressions, relative skill ratio, equals the log of (one plus) the relative skill composition of natives to immigrants. ${ }^{37}$ The higher the relative skill ratio, the more unskilled immigrants are compared to natives. ${ }^{38}$

The indirect measure we employ for the relative skill composition of natives to immigrants is the (log) per capita GDP of the destination country in 1995 (PPP-adjusted), from the World Development Indicators. Consider the standard international migration model with no productivity differences across countries. From a theoretical point of view, in this case the relationship between destination countries' per capita GDP and immigrants' skill mix (relative to natives) is unambiguous. High per capita GDP countries have a higher supply of skilled to unskilled labor than low per capita GDP countries, therefore lower skilled wages and higher unskilled wages. This creates an incentive for unskilled migrants to move from low to high per capita GDP countries, while skilled migrants will tend to move in the opposite direction. Therefore, this simple model predicts that the relative skill composition of natives to immigrants is high in higher-income countries and low in lower-income countries. If we drop the unrealistic assumption of equal technology levels across economies, the pattern of international migration in terms of skill composition is ambiguous, since rates of return can be higher-than in the rest of the world-for both types of labor in a technologically advanced country. Therefore, in general, the relationship between destination countries' per capita GDP and the relative skill composition of natives to immigrants becomes an empirical question. Based on a sample of fourteen countries, for which data on both variables are available (OECD, 1997), Mayda (2006, figure 1) shows that per capita GDP in

\footnotetext{
${ }^{36}$ ISCED level 02 usually refers to individuals who have completed the ninth grade.

${ }^{37}$ In terms of the notation in the theoretical model, the relative skill ratio equals $\log \left(1+\beta_{U} / \beta_{S}\right)$ where $\beta_{U} / \beta_{S}>1$ if and only if $\beta_{U}>1$ (this is the case of unskilled immigration).

${ }^{38}$ The relative skill ratio measure is likely to understate the actual skill level of natives to immigrants, in all countries, for two reasons. First, the immigration statistics used are for legal migration. Second, educated immigrants often work in occupations that require lower skills than their education level.
} 
1995 is indeed positively and significantly correlated with the relative skill composition for the same year. Based on this evidence, we can therefore use per capita GDP levels as a proxy for the relative skill mix. Our first set of estimates is based on the latter indirect measure, as it is available for a larger number of countries. Robustness checks in table 7 use the direct measure for the relative skill composition described above.

We also test the predictions of our model using information on the size of destination countries' welfare states (labor tax rates and per capita benefits), which comes from two sources. Data on labor tax rates are taken from Mendoza, Razin, and Tesar (1994), as extended by MilesiFerretti, Mendoza, and Asea (1997) and Daveri and Tabellini (2000). To compute average labor income tax rates, these papers use fiscal revenue statistics. Figures on per capita transfers are taken from Razin, Sadka, and Swagel (2002) and are based on the OECD analytical database. Per capita transfers include both social security and other transfers, such as unemployment and disability compensation, and are deflated using each country's CPI, and expressed in 1990 PPP equivalent dollars.

In order to measure how redistributive a welfare system is, we construct an indicator of the progressivity of the tax system in the host countries, which is based on data from OECD (1998). In particular, we use information on average income tax rates (that is, personal income tax due as a fraction of gross wage earnings) for single individuals without children who earn, respectively, $67 \%$ and $167 \%$ of the annual wage earnings of an average production worker (see table 1 in OECD, 1998). Our measure of the progressivity of the tax system, progressivity, equals the difference in tax rates applied to these two groups.

Finally, we complement our investigation based on the ISSP survey using an additional individual-level data set, the 2002-2003 round of the European Social Survey (ESS), which covers a different (and larger) sample of countries than the ISSP ${ }^{39}$ and was run in a different period of time. ${ }^{40}$ The immigration question we examine in the ESS data set is also more specific than the one contained in the ISSP, as it focuses on immigrants of the same race or ethnic group as the majority in the country. ${ }^{41}$ The main advantage of this more narrowly phrased question is that it abstracts from racial and ethnic considerations, which could bias the esti-

\footnotetext{
${ }^{39}$ As with the ISSP data set, we restrict the ESS sample and only focus on higher-income countries: Austria, Belgium, (Czech Republic, Denmark, Finland, France, Germany, Greece, Hungary, Ireland, Israel, Italy, Luxembourg, Netherlands, Norway, Portugal, Spain, Sweden, Switzerland, United Kingdom, Slovenia.

${ }^{40}$ For more information on the construction of the survey, see Jovell et al. (2003). The data are available from the Norwegian Social Science Data Services.

${ }^{41}$ In particular, the survey asks: "To what extent do you think [country] should allow people of the same race or ethnic group as most [country] people to come and live here? 1. Allow many immigrants to come and live here; 2. Allow some; 3. Allow a few; 4. Allow none; 7. Refusal; 8. Don't know; 9. No answer."
}

mates on individual skill and income. On the other hand, the disadvantage of the ESS data set is that the income variable is not continuous, therefore it is subject to measurement error. ${ }^{42}$

As before, we exclude nonnationals from the sample and construct a dichotomous variable, pro-immig dummy-ESS, which equals 1 if the individual would like many or some immigrants (of the same race and ethnic group as the majority), 0 otherwise (that is, if the individual would like a few immigrants or none). Summary statistics of pro-immig dummy-ESS and the other ESS variables included in the regressions are presented in table 3 . The different picture these numbers portray relative to the ISSP data set-in particular, the higher fraction of individuals in favor of migration-is not surprising given that in the ESS survey the immigration question is asked in relation to immigrants of the same race and ethnic group as the majority.

Using pro-immig dummy-ESS as the dependent variable, we estimate probit models which include, as regressors, country dummy variables and have robust standard errors clustered by country. ${ }^{43}$ We combine the European Social Survey with aggregate statistics on the destination countries of immigrant flows. Data on per capita GDP of the destination country in 2002 (PPP-adjusted) have been obtained from the World Development Indicators data set. The relative skill ratio variable is constructed using 2002-2003 data on native and immigrant populations by level of education (lower secondary education, upper secondary, tertiary) from table I.12 in SOPEMI (2005).

\section{Empirical Results}

As the theoretical model shows, the impact of immigration on natives' preferences through the welfare-state channel is a function of individual income. On the other hand, the effect of immigration on natives' attitudes through the labor market channel is a function of individual skill. In our empirical specifications, we will use both variables to disentangle the two effects. Notice that, besides employment income, our individual-level measure of real income also includes interests and dividends, rents received on real estate, and the like. Thus, while not surprisingly individual income and individual skill are positively and significantly correlated, ${ }^{44}$ they are far from being perfectly collinear, which makes it possible to analyze them in conjunction.

In particular, the theoretical models in section III derive the following predictions. Through the welfare-state channel, if per capita transfers are fixed, tax rates are adjustable, and the tax system is redistributive (tax adjustment model), the more affluent an individual is, the less favorable he should be to immigration if he resides in a country where

\footnotetext{
${ }^{42}$ See definition of income in the footnote to table 3.

${ }^{43}$ As recommended on the ESS Web site, our estimation uses both design and population size weights.

${ }^{44}$ Their correlation coefficient in the overall ISSP sample is 0.34 (significant at the $1 \%$ level).
} 
TABle 3A.-Summary Statistics of Individual-LeVel Variables (ESS Data Set)

\begin{tabular}{|c|c|c|c|c|c|}
\hline Variable & Obs & Mean & Std. Dev. & Min & $\operatorname{Max}$ \\
\hline Pro-immig dummy & 29,248 & 0.6451 & 0.4785 & 0.0000 & 1.0000 \\
\hline Year of birth & 29,248 & 1955 & 18 & 1893 & 1988 \\
\hline Male & 29,248 & 0.4838 & 0.4997 & 0.0000 & 1.0000 \\
\hline Real income & 29,248 & 2.8104 & 1.7746 & 0.1111 & 12.0000 \\
\hline Education (highest level attained) & 29,248 & 2.9800 & 1.4845 & 0.0000 & 6.0000 \\
\hline
\end{tabular}

These summary statistics do not use design and population size weights.

Table 3B.-Summary Statistics of Individual-Level Variables by Country (ESS) AND of Country-Level Variables

\begin{tabular}{|c|c|c|c|c|c|c|}
\hline Country & $\begin{array}{l}\text { Pro-Immig } \\
\text { Dummy }\end{array}$ & Education & Real Income & $\begin{array}{c}\text { Per Capita } \\
\text { GDP }\end{array}$ & $\begin{array}{l}\text { Relative Skill } \\
\text { Composition }\end{array}$ & Benefits \\
\hline Luxembourg & 0.5429 & 2.6379 & 3.4873 & 59,977 & 2.0547 & 8310.9470 \\
\hline Ireland & 0.7775 & 2.7174 & 1.8867 & 35,653 & 0.4043 & 3587.3380 \\
\hline Norway & 0.7119 & 3.4791 & 3.7711 & 34,750 & 1.4222 & 6951.4750 \\
\hline Switzerland & 0.7981 & 3.2322 & 4.5611 & 31,020 & 5.1932 & 7505.3120 \\
\hline Netherlands & 0.6310 & 2.9866 & 3.4162 & 29,550 & 1.6595 & 5543.4070 \\
\hline Austria & 0.4276 & 3.2512 & 3.0337 & 29,015 & 3.1415 & 6189.7400 \\
\hline Denmark & 0.7482 & 3.1962 & 3.5789 & 28,957 & 1.1638 & 7317.9740 \\
\hline Belgium & 0.6764 & 3.0236 & 2.8084 & 27,459 & 1.8042 & 5709.0030 \\
\hline United Kingdom & 0.6345 & 2.9809 & 3.7550 & 27,176 & 2.0380 & 5042.1450 \\
\hline France & 0.6331 & 2.9979 & 2.3630 & 26,613 & 3.5085 & 6309.9100 \\
\hline Sweden & 0.8866 & 2.9907 & 3.2947 & 26,468 & 1.4150 & 6587.4060 \\
\hline Finland & 0.5808 & 2.8742 & 3.2209 & 26,018 & 1.2446 & 5775.8980 \\
\hline Italy & 0.7053 & 2.3389 & 2.2621 & 25,554 & & 5269.5770 \\
\hline Germany & 0.7188 & 3.3340 & 3.2395 & 25,546 & 5.6564 & 6065.6310 \\
\hline Spain & 0.5433 & 2.1593 & 2.1309 & 22,445 & 0.5475 & 3273.5390 \\
\hline Israel & 0.7989 & 3.5000 & 1.9656 & 22,003 & & \\
\hline Greece & 0.2754 & 2.2421 & 2.1162 & 18,834 & 0.8266 & 3082.1880 \\
\hline Portugal & 0.4377 & 1.7066 & 2.0345 & 18,398 & 0.3275 & 2745.0350 \\
\hline Slovenia & 0.6581 & 3.3278 & 1.5314 & 18,018 & & \\
\hline Czech Republic & 0.5474 & 3.0845 & 1.8317 & 16,556 & 2.6415 & 2444.1780 \\
\hline Hungary & 0.4942 & 2.2740 & 1.0678 & 14,159 & 0.6698 & \\
\hline
\end{tabular}

Pro-immig dummy equals 1 if the individual would like many or some immigrants (of the same race and ethnic group as the majority), 0 otherwise (that is, if the individual would like a few immigrants or none). Real income is household's total net income (expressed on a scale from 1 to 12) divided by the number of household members. Education (highest level attained) goes from 0 to 6 (not completed primary education; primary or first stage of basic; lower secondary or second stage of basic; upper secondary; postsecondary, nontertiary; first stage of tertiary; second stage of tertiary). Per capita gdp in 2002 (PPP, constant 2000 international dollar) is from the World Bank.

The relative skill composition (RSC) is the ratio of skilled to unskilled labor in the native relative to the immigrant populations. For both natives and immigrants, the ratio of skilled to unskilled labor is measured as the ratio of the number of individuals with upper secondary or tertiary education to the number of individuals with lower secondary education. The RSC uses data on the stock of immigrants and natives in 2002-2003 (OECD, 2005). Benefits is per capita social expenditure in 1998 (at constant 1995 prices and PPP-adjusted).

These summary statistics do not use design and population size weights.

natives are on average more skilled than immigrants. Thus, in such countries, the relationship between individual income and pro-immigration attitudes should be negative. On the other hand, according to the tax adjustment model, richer households should favor immigration more than poorer households in countries characterized by skilled migration. Therefore, in such countries, we would expect a positive correlation between individual income and opinions in favor of immigrants (proposition 1). Next, consider the benefit adjustment model - that is, a model in which the adjustment in the fiscal position of the welfare state to immigration takes place through changes in per capita welfare benefits with tax rates kept fixed. Still assuming a redistributive tax system, the correlations between income and pro-immigration attitudes should have exactly the opposite signs for each type of skill mix of natives to immigrants. We should observe a positive relationship between income and pro-immigration attitudes in countries with unskilled immigrants relative to natives and a negative relationship in countries with skilled immigrants relative to natives (proposition 2). Finally, through the labor market channel, skilled (unskilled) individuals should be in favor of (against) immigrants in destinations characterized by unskilled immigration. Therefore we should observe a positive correlation between skill and pro-immigration attitudes in these countries. The opposite is true for countries where immigrants are skilled relative to natives. These predictions are summarized in table 4 .

We bring these theoretical predictions to the data in tables 5 and 6-8. We investigate the empirical validity on average $^{45}$ of either one of the two welfare-state models, controlling for the impact of labor market effects.

Our initial set of regressions (columns 1-4, table 5), where we assume a common coefficient on individual-level variables across countries, illustrate basic patterns in the data. Ceteris paribus, older individuals and women are less likely to favor immigrant inflows, even though the latter effect is not always

\footnotetext{
45 In our analysis, because of the low number of country observations, we assume that all countries follow either the first model or the second one. In other words, we test the validity of each model on average across countries.
} 
Table 4.-Correlations between Pro-Immigration Attitudes and, Respectively, Skill and Income through the Labor Market AND THE Welfare-STATE CHANNELS

\begin{tabular}{|c|c|c|c|c|c|c|}
\hline \multirow[t]{2}{*}{$\begin{array}{l}\text { Relative Skill } \\
\text { Composition }\end{array}$} & \multicolumn{3}{|c|}{ Skilled Immigration } & \multicolumn{3}{|c|}{ Unskilled Immigration } \\
\hline & & \multicolumn{2}{|c|}{ Welfare State } & & \multicolumn{2}{|c|}{ Welfare State } \\
\hline Channel & $\begin{array}{l}\text { Labor } \\
\text { Market }\end{array}$ & $\begin{array}{c}\text { Tax Adjustment } \\
\text { Model }\end{array}$ & $\begin{array}{c}\text { Benefit Adjustment } \\
\text { Model }\end{array}$ & $\begin{array}{l}\text { Labor } \\
\text { Market }\end{array}$ & $\begin{array}{c}\text { Tax Adjustment } \\
\text { Model }\end{array}$ & $\begin{array}{c}\text { Benefit Adjustment } \\
\text { Model }\end{array}$ \\
\hline $\begin{array}{l}\text { Corr. b/w attitudes } \\
\text { and Skill } \\
\text { Corr. b/w attitudes } \\
\text { and Income }\end{array}$ & Negative & Positive & Negative & Positive & Negative & Positive \\
\hline
\end{tabular}

Table 5.-Welfare-State and Labor Market Determinants Using an Indirect Measure of the Relative Skill Composition (ISSP Data Set)

\begin{tabular}{|c|c|c|c|c|c|c|c|}
\hline $\begin{array}{l}\text { Probit with country dummy } \\
\text { variables }\end{array}$ & 1 & 2 & 3 & 4 & 5 & 6 & 7 \\
\hline$\underline{\text { Dependent variable }}$ & \multicolumn{7}{|c|}{$\underline{\text { Pro-Immig Dummy }}$} \\
\hline Age & $\begin{array}{l}-0.0074 \\
0.0017 * * *\end{array}$ & $\begin{array}{l}-0.0035 \\
0.0014 * *\end{array}$ & $\begin{array}{l}-0.0031 \\
0.0015^{* *}\end{array}$ & $\begin{aligned}-0.0043 \\
0.0025^{*}\end{aligned}$ & $\begin{array}{l}-0.0039 \\
0.0015^{* * *} *\end{array}$ & $\begin{array}{l}-0.0038 \\
0.0015^{* * *}\end{array}$ & $\begin{array}{l}-0.0034 \\
0.0015^{* *}\end{array}$ \\
\hline Male & $\begin{array}{l}0.0474 \\
0.0412\end{array}$ & $\begin{array}{l}0.0739 \\
0.0413^{*}\end{array}$ & $\begin{array}{l}0.1062 \\
0.0414 * *\end{array}$ & $\begin{array}{l}0.0609 \\
0.0614\end{array}$ & $\begin{array}{l}0.0773 \\
0.0419 *\end{array}$ & $\begin{array}{l}0.0756 \\
0.0419 *\end{array}$ & $\begin{array}{l}0.1063 \\
0.0425^{* *}\end{array}$ \\
\hline Log of real income & $\begin{array}{l}0.1243 \\
0.0385 * * *\end{array}$ & $\begin{array}{l}0.0192 \\
0.0381\end{array}$ & $\begin{array}{l}0.0205 \\
0.0418\end{array}$ & $\begin{array}{r}-0.0032 \\
0.0622\end{array}$ & $\begin{array}{l}\mathbf{0 . 0 2 0 6} \\
\mathbf{0 . 0 3 8 2}\end{array}$ & $\begin{array}{l}2.0979 \\
1.0828 *\end{array}$ & $\begin{array}{l}2.3693 \\
1.0895 * *\end{array}$ \\
\hline Log of real income $\times$ gdp & & & & & & $\begin{array}{r}-0.2099 \\
0.1102 *\end{array}$ & $\begin{array}{l}-\mathbf{0 . 2 3 7 1} \\
\mathbf{0 . 1 1 0 7} * *\end{array}$ \\
\hline Education (years of education) & & $\begin{array}{l}0.073 \\
0.0133 * * *\end{array}$ & $\begin{array}{l}0.0512 \\
0.0112 * * *\end{array}$ & $\begin{array}{l}0.0697 \\
0.0169 * * *\end{array}$ & $\begin{aligned}- & 1.0792 \\
& 0.4279 * *\end{aligned}$ & $\begin{aligned}-1.2332 \\
0.4315 * * *\end{aligned}$ & $\begin{array}{l}-1.169 \\
0.4205 * * *\end{array}$ \\
\hline Education $\times$ gdp & & & & & $\begin{array}{l}0.1168 \\
0.0435^{* * * *}\end{array}$ & $\begin{array}{l}0.1324 \\
0.0439 * * *\end{array}$ & $\begin{array}{l}0.1236 \\
0.0428 * * *\end{array}$ \\
\hline Pro-immig crime & & & $\begin{array}{l}0.5016 \\
0.0783^{* * *} *\end{array}$ & & & & $\begin{array}{l}0.498 \\
0.0801 * * *\end{array}$ \\
\hline Pro-immig culture & & & $\begin{array}{l}0.5913 \\
0.0876^{* * * *}\end{array}$ & & & & $\begin{array}{l}0.593 \\
0.0883 * * *\end{array}$ \\
\hline Upper social class & & & & $\begin{array}{l}0.0426 \\
0.0237 *\end{array}$ & & & \\
\hline Trade union member & & & & $\begin{array}{l}0.0086 \\
0.0505\end{array}$ & & & \\
\hline Political affiliation with the right & & & & $\begin{array}{l}-0.1561 \\
0.0566^{* * * *}\end{array}$ & & & \\
\hline Observations & 13,605 & 13,605 & 13,605 & 6,364 & 13,605 & 13,605 & 13,605 \\
\hline Pseudo $R$-squared & 0.1 & 0.12 & 0.18 & 0.13 & 0.13 & 0.13 & 0.18 \\
\hline
\end{tabular}

significant. These first results also show that it is problematic to analyze the welfare-state variable on its own, independently from labor market and noneconomic determinants of immigration attitudes. Richer individuals are usually better educated than poorer ones, which has implications for their position in the labor market and for their view of immigration from a cultural and security point of view. For example, controlling only for the age and gender of the respondent, we estimate a positive and significant coefficient on income in regression 1. However, once we also account for the impact of individual skill (equation [2]) and of other noneconomic determinants of immigration preferences that are correlated with income (pro-immig crime and pro-immig culture in regression 3; upper social class, trade union member, political affiliation with the right in regression 4), the effect of income becomes insignificant.

We next let the coefficients on individual skill and income change by country, as suggested by the theory (re- gressions 5-7). In these regressions, we use per capita GDP as a proxy for the relative skill mix of natives to immigrants. Since data on per capita GDP are available for all countries analyzed, the sample size is not affected. In particular, in column 6 , we estimate the following probit model: ${ }^{46}$

$$
\begin{aligned}
& \operatorname{Prob}\left(\text { pro-immig dummy }_{i}=1 \mid x_{i}\right)= \\
& =\Phi\left(\beta_{1} \text { age }_{i}+\beta_{2} \text { male }_{i}+\beta_{3} \text { income }_{i}+\beta_{4} \text { income }_{i}\right. \\
& \left.\quad \times p c g d p^{c}+\beta_{5} e d u c_{i}+\beta_{6} \text { educ }_{i} \times p c g d p^{c}\right),
\end{aligned}
$$

${ }^{46}$ This specification, as well as all the other ones in the paper, also includes country dummy variables as regressors. 
TABle 6.-The Country-Specific Impact of Education and Income on Immigration Attitudes (ISSP Data Set)

\begin{tabular}{|c|c|c|c|}
\hline Country & Marginal Effect of Education & Marginal Effect of Log Real Income & Per Capita GDP \\
\hline USA & $0.0091\left[\begin{array}{lll}0.0069 & 0.0116\end{array}\right]$ & $-0.0046[-0.01170 .0019]$ & 27,395 \\
\hline Norway & $0.0093[0.00730 .0116]$ & $-0.0031[-0.00980 .0035]$ & 24,694 \\
\hline Japan & $0.0179\left[\begin{array}{lll}0.0142 & 0.0217\end{array}\right]$ & $-0.0035[-0.01630 .0094]$ & 23,212 \\
\hline Canada & $0.0110\left[\begin{array}{lll}0.0091 & 0.0132\end{array}\right]$ & $-0.0020[-0.00980 .0058]$ & 23,085 \\
\hline Austria & $0.0060[0.00430 .0080]$ & $-0.0002[-0.00440 .0042]$ & 22,090 \\
\hline Germany West & $0.0030\left[\begin{array}{llll}0.0020 & 0.0042\end{array}\right]$ & $0.0002[-0.00190 .0024]$ & 21,479 \\
\hline Germany East & $0.0025\left[\begin{array}{llll}0.0014 & 0.0040]\end{array}\right.$ & $0.0002[-0.00160 .0020]$ & 21,479 \\
\hline Netherlands & $0.0040\left[\begin{array}{lll}0.0031 & 0.0051\end{array}\right]$ & $0.0007\left[\begin{array}{lll}-0.0023 & 0.0037\end{array}\right]$ & 20,812 \\
\hline Sweden & $0.0057\left[\begin{array}{lll}0.0043 & 0.0073\end{array}\right]$ & $0.0021[-0.00250 .0069]$ & 20,031 \\
\hline Great Britain & $0.0035\left[\begin{array}{lll}0.0023 & 0.0050\end{array}\right]$ & $0.0017[-0.00140 .0050]$ & 19,465 \\
\hline New Zealand & $0.0052\left[\begin{array}{lll}0.0036 & 0.0069\end{array}\right]$ & $0.0064\left[\begin{array}{lll}-0.0001 & 0.0133\end{array}\right]$ & 17,706 \\
\hline Ireland & $0.0066\left[\begin{array}{lll}0.0046 & 0.0089\end{array}\right]$ & $0.0102\left[\begin{array}{lll}0.0003 & 0.0203\end{array}\right]$ & 17,264 \\
\hline Spain & $0.0033[0.00090 .0058]$ & $0.0139\left[\begin{array}{lll}0.0033 & 0.0257\end{array}\right]$ & 15,163 \\
\hline Slovenia & $0.0001\left[\begin{array}{lll}-0.0009 & 0.0012]\end{array}\right.$ & $0.0077\left[\begin{array}{lll}0.0016 & 0.0156\end{array}\right]$ & 12,978 \\
\hline Czech Republic & $-0.0003\left[\begin{array}{lll}-0.0022 & 0.0015]\end{array}\right.$ & $0.0138\left[\begin{array}{lll}0.0028 & 0.0271\end{array}\right]$ & 12,426 \\
\hline Hungary & $-0.0027[-0.0055-0.0004]$ & $0.0198\left[\begin{array}{lll}0.0027 & 0.0434]\end{array}\right]$ & 9,315 \\
\hline Slovak Republic & $-0.0113[-0.0231-0.0023]$ & $0.0634\left[\begin{array}{lll}0.0082 & 0.1424\end{array}\right]$ & 8,487 \\
\hline
\end{tabular}

This table presents the marginal effects (and corresponding $90 \%$ confidence intervals in brackets) of education and log real income, country by country (ISSP data set). To calculate the marginal effects of education and log real income, we have used Clarify and have set all the individual-level variables equal to their overall-sample means (see table 1). For the aggregate-level variables we have used each country's specific values, that is each country's per capita GDP and coefficient on the country dummy variable. The marginal effects in this table are based on the coefficient estimates of regression 7 , table 5 .

where $\Phi(\cdot)$ represents the cumulative distribution function of a standard normal, $\beta$ is a vector of parameters to be estimated, and $x_{i}$ is the vector of all explanatory variables specific to individual $i$, who is from country $c$. In regression 7 , we augment this specification by adding the two regressors pro-immig crime and pro-immig culture. Based on these specifications, we find evidence of substantial cross-country heterogeneity in terms of the impact of both skill and income. The effect of the two variables is characterized by the opposite pattern across countries. Our estimates show that, while the impact of education on pro-immigration preferences is positive in higher per capita GDP countries $\left(\beta_{6}>0\right)$ and negative in lower per capita GDP countries $\left(\beta_{5}<0\right)$, the effect of individual income is negative in higher per capita GDP countries $\left(\beta_{4}<0\right)$ and positive in lower per capita GDP countries $\left(\beta_{3}>0\right){ }^{47}$ Therefore, our results are consistent with a labor market plus welfare-state explanation of attitudes toward immigrants in a framework characterized by fixed welfare benefits, adjustable welfare costs (tax rates), and a redistributive fiscal system (tax adjustment model).

We confirm that the estimated coefficients in regression 7 imply the above-stated effects for countries in our sample, i.e., the threshold values of per capita GDP such that the correlations change sign fall within the range of values in our sample. We find that $p c g d p_{E}^{*}$ such that $\left(\beta_{5} e d u c_{i}+\right.$ $\left.\beta_{6} e d u c_{i} \times p c g d p_{E}^{*}\right)=0$ equals $\$ 12,809$ and that $p c g d p_{I}^{*}$ such that $\left(\beta_{3}\right.$ income $_{i}+\beta_{4}$ income $_{i} \times$ pcgdp $\left.{ }_{\text {İ }}\right)=0$ equals $\$ 21,869$. These threshold values are also consistent with

\footnotetext{
${ }^{47}$ Using the coefficient estimates of regression 7, we calculate the marginal effects for income and education and their interaction variables and find that they are of the same sign as the corresponding coefficients. To calculate the marginal effects of interaction variables, we use the Stata command predictnl which gets around the problems pointed out in $\mathrm{Ai}$ and Norton (2003).
}

table 6, which reports the marginal effects of education and income at different values of GDP per capita (the marginal effects are based on the coefficient estimates of regression 7). ${ }^{48}$ We find that, for example, while in the United States doubling real income decreases the probability that the respondent is pro-immigration by 0.5 percentage points, in the Slovak Republic it increases it by 6. In the United States, one more year of education raises the likelihood by 1 percentage point, whereas in the Slovak Republic it decreases it by 1.1 percentage points. While these numbers appear small, they are large in relation to the mean of the dependent variable which is only 7.9 percentage points.

Next, we use the marginal effects from table 6 in figure 1, which provides additional evidence on the cross-country pattern of the impact of skill and income. In particular, we plot the estimated marginal effects of education (income) on the top (bottom) panel of figure 1 as a function of the 1995 per capita GDP of the destination country. The top graph shows a positive and significant (at the $1 \%$ level) correlation between the host country's per capita GDP and the size of

\footnotetext{
${ }^{48}$ To calculate the marginal effects of education and income, we have used Clarify. This is a routine that draws 1,000 sets of coefficients from a multivariate normal with mean equal to the maximum likelihood coefficient estimates (the beta hats) and variance equal to the variance covariance matrix of these estimates. For each of the 1,000 sets of parameters, Clarify calculates two probabilities: first, the predicted pro-immigration probability when all the individual-level variables are equal to their overall sample means and the aggregate level variables are equal to each country's specific values (each country's per capita GDP and coefficient on the country dummy variable); second, the predicted pro-immigration probability when either the real income measure is doubled or the measure of education is augmented by one unit, while all other individual-level characteristics are held fixed. Clarify then computes the difference between the latter and the former predicted probabilities. Finally, Clarify provides the sample mean-which represents the marginal effect-standard errors and corresponding confidence intervals over the distribution of 1,000 values of the difference in probabilities.
} 
Figure 1.-The Country-Specific Impact of Education and Income on Immigration AtTitudes (ISSP)

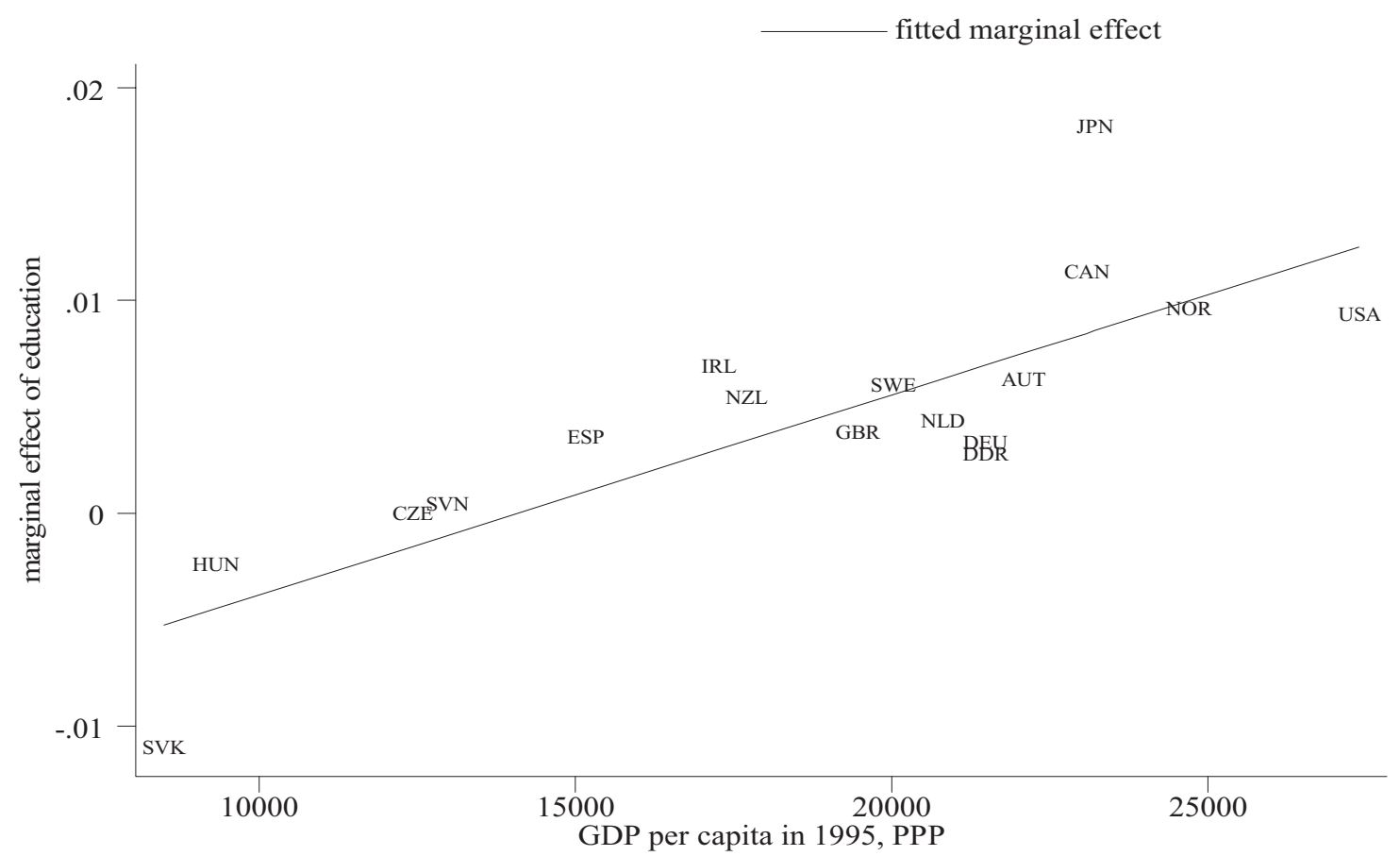

This figure is based on the MEs in table 6. The slope of the line is 9.41e-07, significant at the 1\% level (robust standard errors). We also estimate the line using WLS (with weights equal to the inverse of the squared standard error of the marginal effect of each country): the sign of the correlation does not change and the level of significance is still $1 \%$.

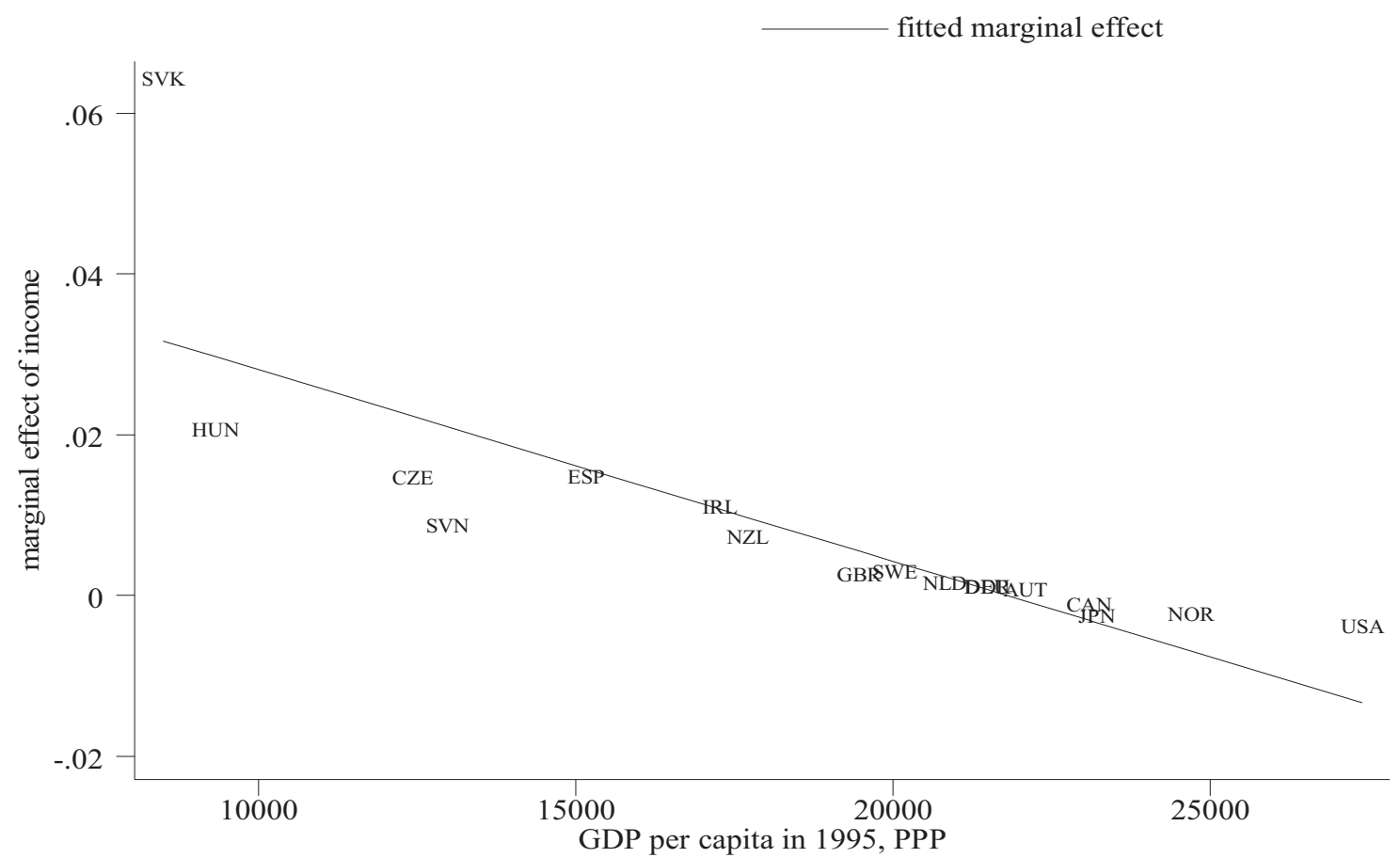

This figure is based on the MEs in table 6. The slope of the line is $-2.38 \mathrm{e}-06$, significant at the $1 \%$ level (robust standard errors). We also estimate the line using WLS (with weights equal to the inverse of the squared standard error of the marginal effect of each country): the sign of the correlation does not change and the level of significance is still $1 \%$.

the effect of education (as in Mayda, 2006). On the other hand, the bottom graph displays the opposite type of pattern, a negative and significant (at the 1\% level) correlation between the destination country's per capita GDP and the marginal effect of income. In other words, the richer the destination country, the more positive the impact of individual skill on pro-immigration attitudes and the more negative the impact of individual income.

Based on the regressors of this specification (regression 7, table 5), we also investigate the relative importance of labor 
Table 7.-Welfare-State and Labor Market Determinants Using a Direct Measure of the Relative Skill Composition (ISSP Data Set)

\begin{tabular}{|c|c|c|c|c|c|c|}
\hline Probit with country dummy variables & 1 & 2 & 3 & 4 & 5 & 6 \\
\hline Dependent variable & \multicolumn{5}{|c|}{ Pro-Immig Dummy } & Pro-Trade Dummy \\
\hline Age & $\begin{array}{l}-0.0054 \\
0.0023 * *\end{array}$ & $\begin{array}{l}-0.0041 \\
0.0020 * *\end{array}$ & $\begin{array}{l}-0.0048 \\
0.0020 * *\end{array}$ & $\begin{array}{l}-0.0047 \\
0.0023 * *\end{array}$ & $\begin{array}{l}-0.0047 \\
0.0019 * *\end{array}$ & $\begin{array}{r}-0.0006 \\
0.0013\end{array}$ \\
\hline \multirow[t]{2}{*}{ Male } & 0.0381 & 0.0803 & 0.0705 & 0.063 & 0.0728 & 0.321 \\
\hline & 0.0521 & 0.0616 & 0.0456 & 0.0552 & 0.0469 & $0.0384 * * *$ \\
\hline \multirow{2}{*}{ Log of real income } & 0.137 & 0.1411 & & & & 0.1203 \\
\hline & $0.0620 * *$ & $0.0770 *$ & & & & $0.0434 * * *$ \\
\hline \multirow[t]{2}{*}{ Log of real income $\times$ relative skill ratio } & -0.1545 & -0.1643 & & & & 0.0574 \\
\hline & $0.0661 * *$ & $0.0774 * *$ & & & & 0.0552 \\
\hline \multirow[t]{2}{*}{ Education (years of education) } & -0.024 & -0.0382 & -0.5194 & -0.4269 & -0.0723 & 0.0391 \\
\hline & $0.0082 * * *$ & $0.0076^{* * * *}$ & $0.1715^{* * *}$ & $0.0990 * * *$ & $0.0434 *$ & $0.0141 * * *$ \\
\hline \multirow[t]{2}{*}{ Education $\times$ relative skill ratio } & 0.1063 & 0.1006 & 0.5254 & 0.5012 & 0.2429 & 0.0359 \\
\hline & $0.0103 * * *$ & $0.0109 * * *$ & $0.3194 *$ & $0.1023 * * *$ & $0.0534 * * *$ & $0.0096^{* * *}$ \\
\hline \multirow[t]{2}{*}{ Education $\times$ benefits } & & & 0.065 & & & \\
\hline & & & $0.0210 * * *$ & & & \\
\hline \multirow[t]{2}{*}{ Education $\times$ relative skill ratio $\times$ benefits } & & & -0.0551 & & & \\
\hline & & & 0.0379 & & & \\
\hline \multirow[t]{2}{*}{ Education $\times$ labor tax rate } & & & & 0.0105 & & \\
\hline & & & & $0.0024 * * *$ & & \\
\hline \multirow{2}{*}{$\begin{array}{l}\text { Education } \times \text { relative skill ratio } \times \text { labor tax } \\
\text { rate }\end{array}$} & & & & -0.0102 & & \\
\hline & & & & $0.0024 * * *$ & & \\
\hline \multirow[t]{2}{*}{ Education $\times$ progressivity } & & & & & 0.0043 & \\
\hline & & & & & 0.0032 & \\
\hline \multirow[t]{2}{*}{ Education $\times$ relative skill ratio $\times$ progressivity } & & & & & -0.0112 & \\
\hline & & & & & $0.0037 * * *$ & \\
\hline \multirow[t]{2}{*}{ Pro-immig crime } & & 0.488 & & & & \\
\hline & & $0.0815^{* * *} *$ & & & & \\
\hline \multirow[t]{2}{*}{ Pro-immig culture } & & 0.6087 & & & & \\
\hline & & $0.1411 * * *$ & & & & \\
\hline Observations & 7,641 & 7,641 & 10,451 & 9,539 & 10,451 & 7,966 \\
\hline Pseudo $R$-squared & 0.13 & 0.19 & 0.13 & 0.13 & 0.13 & 0.1 \\
\hline
\end{tabular}

market and welfare-state determinants of attitudes. We estimate a linear (OLS) regression using the ordered variable immig opinion as the dependent variable. ${ }^{49} \mathrm{We}$ start with a specification that only includes the sociodemographic, noneconomic, and labor market regressors (age, male, educ, educ $\times$ pcgdp, pro-immig crime, pro-immig culture plus country dummy variables) and next add the welfare-state variables (income, income $\times p c g d p$ ). The difference between the two $R^{2}$ measures is the fraction of the total variance that is explained by public-finance drivers, after accounting for the contribution of sociodemographic, noneconomic, and labor market determinants plus country dummy variables. If we repeat the same exercise including first the sociodemographic, noneconomic, and welfare-state regressors plus country dummy variables, and next the labor market variables, the $R^{2}$ increases by slightly more than before. ${ }^{50}$ Therefore, while this paper uncovers the significant role played by public-finance issues across countries, it also finds that labor market determinants are marginally more important than welfare-state variables, in terms of variance explained.

\footnotetext{
${ }^{49}$ Immig opinion ranges from $1=$ "reduced a lot" to $5=$ "increased a lot."

${ }^{50}$ The difference in the two changes of $R^{2}$ is half of a percentage point.
}

In table 7, we check the robustness of our results in a number of ways. ${ }^{51}$ First, in place of per capita GDP, we use the direct measure of the relative skill composition of natives to immigrants described in section IV (regressions 1 and 2). ${ }^{52}$ Although these estimates are based on a smaller sample of countries because of data limitations, ${ }^{53}$ they are characterized by the same sign patterns as those using per capita GDP and by the same levels of significance (this is true for both the labor market and welfare-state variables). Based on specification 2, the estimates for income $(0.1411$, significant at the $10 \%$ level) and income $*$ relative skill ratio $(-0.1643$, significant at the $5 \%$ level) imply that individuals

${ }^{51}$ For numerous additional robustness checks of the labor market results, see Mayda (2006). For example, Mayda (2006) shows that the correlation between education and pro-immigration preferences disappears if the sample is restricted to individuals out of the labor force. This says that the effect of skill is indeed working through the labor market channel. The labor market results are also confirmed when data on individual occupation are used: respondents in occupations that experience a higher inflow of immigrants are less likely to be pro-immigration (Mayda, 2006).

52 The skill composition of immigrants is shaped by migration policy which, in turn, is a function of attitudes. However, in an individual-level analysis such as this one, reverse causality is not an issue, since each individual has an infinitesimal impact on the aggregate policy outcome.

${ }^{53}$ Regressions 1 and 2 are based on the following countries: Austria, Canada, Germany East, Germany West, Great Britain, Ireland, Netherlands, Spain, Sweden. 
Table 8.-The Country-Specific Impact of Education and Income on Immigration Attitudes (ISSP Data SeT)

\begin{tabular}{|c|c|c|c|}
\hline Country & Marginal Effect of Education & Marginal Effect of Log Real Income & Relative Skill Composition \\
\hline Germany West & $0.0064[0.00440 .0089]$ & $-0.0047[-0.0093-0.0002]$ & 4.0923 \\
\hline Germany East & $0.0050[0.00270 .0081]$ & $-0.0036[-0.0073-0.0001]$ & 4.0923 \\
\hline Netherlands & $0.0068\left[\begin{array}{ll}0.0054 & 0.0083\end{array}\right]$ & $-0.0046\left[\begin{array}{lll}-0.0100 & 0.0008\end{array}\right]$ & 2.6941 \\
\hline Austria & $0.0088\left[\begin{array}{ll}0.0064 & 0.0115]\end{array}\right]$ & $-0.0055[-0.01230 .0013]$ & 2.5329 \\
\hline Great Britain & $0.0069\left[\begin{array}{lll}0.0045 & 0.0097\end{array}\right]$ & $-0.0040[-0.01060 .0017]$ & 2.2523 \\
\hline Canada & $0.0108\left[\begin{array}{lll}0.0087 & 0.0130\end{array}\right]$ & $-0.0034[-0.01420 .0071]$ & 1.6709 \\
\hline Sweden & $0.0057\left[\begin{array}{llll}0.0040 & 0.0077\end{array}\right]$ & $0.0003\left[\begin{array}{llll}-0.0067 & 0.0074\end{array}\right]$ & 1.3362 \\
\hline Spain & $0.0001\left[\begin{array}{lll}-0.0030 & 0.0037\end{array}\right]$ & $0.0145[-0.00020 .0321]$ & 0.4668 \\
\hline Ireland & $-0.0010\left[\begin{array}{lll}-0.0051 & 0.0032\end{array}\right]$ & $0.0195\left[\begin{array}{lll}0.0005 & 0.0401]\end{array}\right]$ & 0.3950 \\
\hline
\end{tabular}

This table presents the marginal effects (and corresponding $90 \%$ confidence intervals in brackets) of education and log real income, country by country (ISSP data set). To calculate the marginal effects of education and $\log$ real income, we have used Clarify and have set all the individual-level variables equal to their overall-sample means (see table 1). For the aggregate-level variables we have used each country's specific values, that is each country's relative skill composition and coefficient on the country dummy variable. The marginal effects in this table are based on the coefficient estimates of regression 2 , table 7.

from countries with relative skill composition above approximately 1.36 are less likely to be in favor of immigration the higher their income, while in countries with relative skill composition below this threshold (Ireland, Spain, and Sweden in our sample), the correlation between proimmigration attitudes and income is positive. ${ }^{54}$ Using the coefficient estimates of regression 2, we calculate the marginal effects of education and income at different values of the relative skill composition (table 8). Figure 2, which plots the two sets of marginal effects as a function of the relative skill composition, provides evidence that is very similar to what we find in figure 1 .

Our next robustness checks exploit the variation across countries in the size and progressivity of the welfare state. In regressions 3-5, table 7, we follow Hanson, Scheve, and Slaughter (2007) and estimate specifications where we use education as a proxy for the level of both individual skill and individual income. In order to differentiate between the labor market hypothesis and the welfare-state one, we use data on the size and progressivity of the welfare state in each destination country. In particular, in column 3, we estimate the following probit model: ${ }^{55}$

$$
\begin{aligned}
& \operatorname{Prob}\left(\text { pro-immig dummy }_{i}=1 \mid x_{i}\right)= \\
& =\Phi\left(\gamma_{1} \text { age }_{i}+\gamma_{2} \text { male }_{i}+\gamma_{3} \text { educ }_{i}+\gamma_{4} \text { educ }_{i} \times \text { RSR }^{c}\right. \\
& \left.\quad+\gamma_{5} \text { educ }_{i} \times \text { benefits }^{c}+\gamma_{6} \text { educ }_{i} \times R S R^{c} \times \text { benefits }^{c}\right),
\end{aligned}
$$

where RSR stands for relative skill ratio and benefits represents per capita benefits in 1995. The two terms $\gamma_{3} e d u c_{i}$ and $\gamma_{4} e d u c_{i} \times R S R^{c}$ capture the labor market effect, while the following two terms $\left(\gamma_{5} e d u c_{i} \times\right.$ benefits $^{c}$ and $\gamma_{6} e d u c_{i} \times$ $R S R^{c} \times$ benefits $\left.^{c}\right)$ provide evidence on the welfare-state channel. If the welfare state is relatively small in a destination country (for example, benefits are equal to 0), we expect the effect of education to reflect only labor market considerations. That is, we should find that the impact of

\footnotetext{
${ }^{54}$ Notice that these results are qualitatively similar when we interact each of the four main terms with the 1995 size of the immigrant inflow, as a fraction of the destination country's population.

55 This specification, as all the other ones in the paper, also includes country dummy variables as regressors.
}

education is positive in countries where natives are more skilled than immigrants on average $\left(\gamma_{4}>0\right)$ and negative in countries where immigrants are more skilled than natives on average $\left(\gamma_{3}<0\right)$. On the other hand, the bigger the size of a destination country's welfare state, the more important welfare-state determinants should be in shaping preferences, and therefore the more likely it is that the effect of education is consistent with propositions 1 or $2 .{ }^{56}$ Recall that, using direct information on income, we found results consistent with the tax adjustment model, where per capita benefits are assumed to be fixed and tax rates adjust following immigration (proposition 1): in this case, higher-income individuals oppose unskilled immigrants and favor skilled ones. Therefore, in regression 3, we should find $\gamma_{6}<0$ and $\gamma_{5}>0$. These are indeed the signs of the terms in education in regression 3. These estimates are based on a limited number of countries, but they provide evidence that is consistent with our previous results, thus confirming their robustness. The two sets of determinants-labor market and welfare-state ones-produce opposite results in terms of the impact of education.

The latter findings are confirmed in specification 4, which uses an alternative measure of the size of the welfare state, that is, labor tax rates. We find that, if labor tax rates are low, the coefficient on education is consistent with the labor market hypothesis (negative and positive in correspondence of, respectively, skilled and unskilled migration) but has the opposite sign if labor tax rates are high, once again strengthening our previous results. Finally, we investigate the same set of issues by differentiating countries according to the progressivity of their tax system (regression 5, table 7). The theoretical model predicts that the income-distribution effects of welfare-state variables should be more pronounced the more redistributive the tax system is (see equations [12] and $[14]) .{ }^{57}$ On the contrary, with zero redistribution, the labor market channel should prevail, even in countries with

\footnotetext{
${ }^{56}$ In addition, the theoretical model predicts that the income-distribution effects of welfare-state variables should be more pronounced the larger the size of the welfare state (see equations [12] and [14]).

${ }^{57}$ Of course, our underlying assumption is that a more progressive tax system is more redistributive.
} 
Figure 2.-The Country-Specific Impact of Education and Income on Immigration AtTitudes (ISSP)

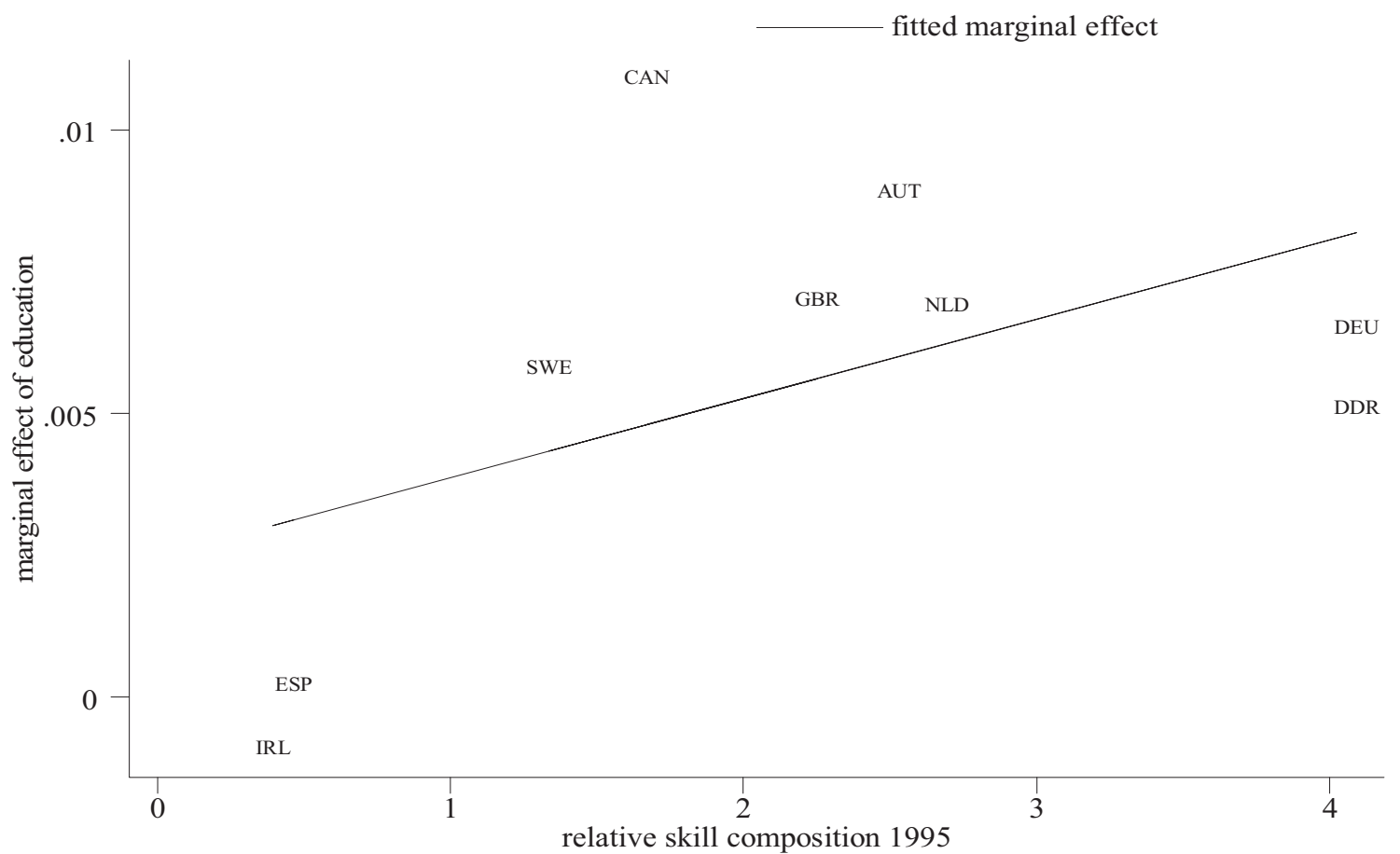

This figure is based on the MEs in table 8 . The slope of the line is 0.0014 , significant at the $16 \%$ level (robust standard errors). We also estimate the line using WLS (with weights equal to the inverse of the squared standard error of the marginal effect of each country): the sign of the correlation does not change, although the significance level decreases.

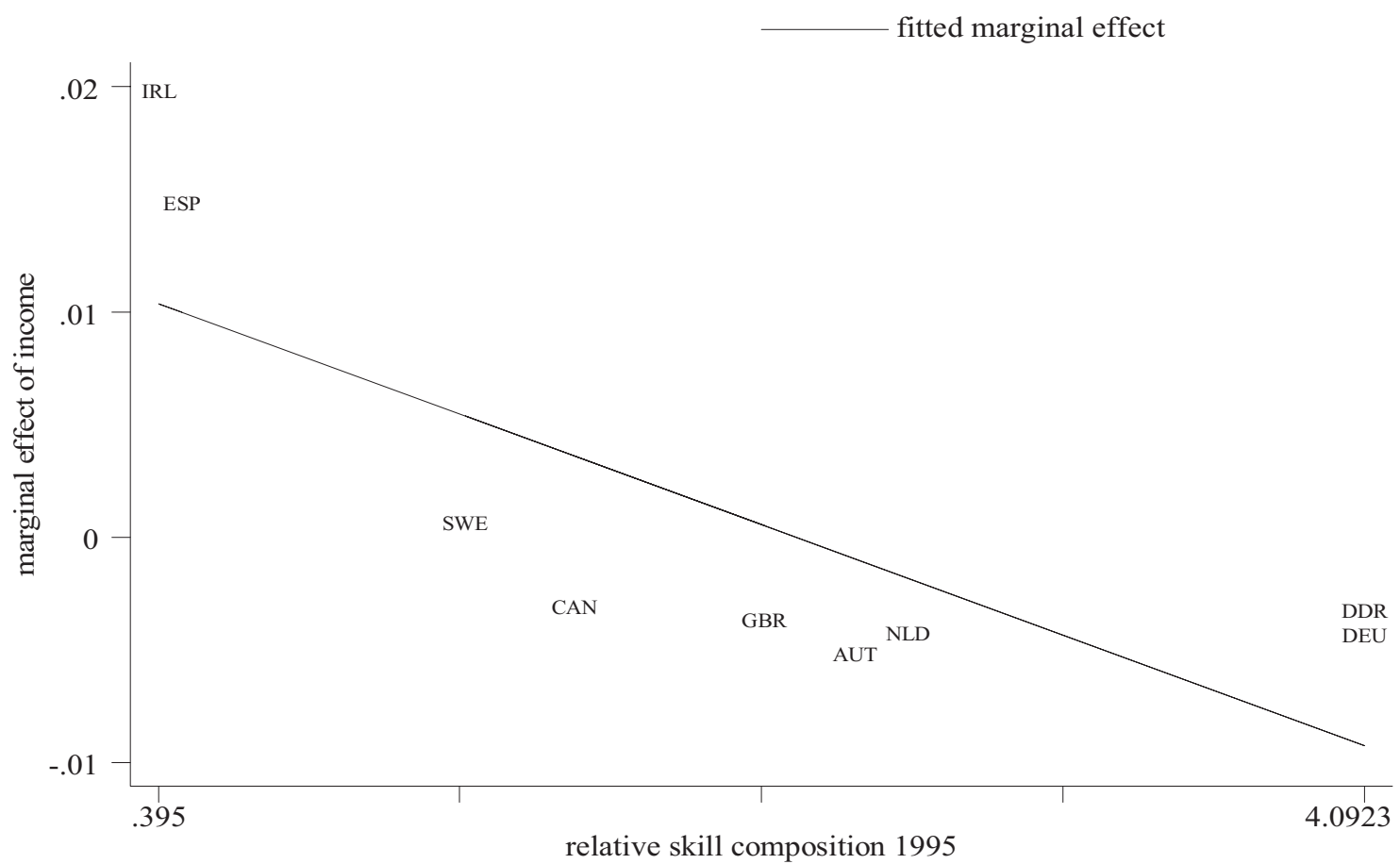

This figure is based on the MEs in table 8 . The slope of the line is -0.0053 , significant at the $2 \%$ level (robust standard errors). We also estimate the line using WLS (with weights equal to the inverse of the squared standard error of the marginal effect of each country): the sign of the correlation does not change and the level of significance is $14 \%$.

sizable welfare states. Our estimates in specification 5 are, once again, consistent with these implications and with our previous results. To conclude, we believe that our main specifications and additional robustness checks provide strong empirical evidence for the interaction of labor market drivers of preferences with welfare-state ones, along the lines of the tax adjustment model.

In the last column of table 7 we consider respondents' preferences with respect to an alternative dimension of globalization, free trade of goods and services. We use the 
TABle 9.-Welfare-State and Labor Market Determinants (ESS Data Set)

\begin{tabular}{|c|c|c|c|c|c|}
\hline Probit with country dummy variables & 1 & 2 & 3 & 4 & 5 \\
\hline Dependent variable & \multicolumn{5}{|c|}{$\underline{\text { Pro Immig Dummy-ESS }}$} \\
\hline \multirow[t]{2}{*}{ Year of birth } & 0.0049 & 0.0084 & 0.0045 & 0.0053 & 0.0063 \\
\hline & $0.0013 * * *$ & $0.0014 * * *$ & $0.0013^{* * *} *$ & $0.0014 * * *$ & $0.0010 * * *$ \\
\hline \multirow[t]{2}{*}{ Male } & 0.0536 & 0.0734 & 0.0512 & 0.0454 & 0.0431 \\
\hline & $0.0296^{*}$ & $0.0286 * *$ & 0.0376 & 0.0437 & 0.0354 \\
\hline \multirow{2}{*}{ Real income } & & 1.3658 & 1.0075 & 0.0229 & \\
\hline & & $0.6598 * *$ & $0.4151 * *$ & $0.0132 *$ & \\
\hline \multirow[t]{2}{*}{ Real income $\times$ gdp } & & -0.1284 & -0.0969 & & \\
\hline & & $0.0647 * *$ & $0.0407 * *$ & & \\
\hline \multirow[t]{2}{*}{ Real income $\times$ relative skill ratio } & & & & -0.0026 & \\
\hline & & & & 0.0087 & \\
\hline \multirow[t]{2}{*}{ Education (highest level attained) } & -1.3381 & & -1.4043 & 0.1047 & -2.7551 \\
\hline & 0.9378 & & $0.8275^{*}$ & $0.0453 * *$ & $1.1820 * *$ \\
\hline \multirow[t]{2}{*}{ Education $\times$ gdp } & 0.1489 & & 0.1562 & & \\
\hline & 0.0921 & & $0.0813^{*}$ & & \\
\hline \multirow[t]{2}{*}{ Education $\times$ relative skill ratio } & & & & 0.0638 & 2.613 \\
\hline & & & & $0.0299 * *$ & $1.2033 * *$ \\
\hline \multirow[t]{2}{*}{ Education $\times$ benefits } & & & & & 0.3423 \\
\hline & & & & & $0.1404 * *$ \\
\hline \multirow[t]{2}{*}{ Education $\times$ relative skill ratio $\times$ benefits } & & & & & -0.3023 \\
\hline & & & & & $0.1407 * *$ \\
\hline Observations & 37,879 & 30,546 & 30,405 & 26,830 & 31,553 \\
\hline Pseudo $R$-squared & 0.07 & 0.05 & 0.07 & 0.08 & 0.08 \\
\hline
\end{tabular}

The sample excludes all individuals who are not citizens of the country where they are interviewed. The table reports coefficient estimates for probit regressions (the constant is not shown). Robust standard errors, clustered by country, are presented under each coefficient. As recommended in the ESS Web site, our estimation uses both design and population size weights. * significant at $10 \% ; * *$ significant at $5 \%$; $* * *$ significant at $1 \%$. All regressions in this table control for country fixed effects. real income is household income (expressed on a scale from 1 to 12) divided by the number of household members. The relative skill ratio is the log of one plus the relative skill composition. The relative skill composition (RSC) is the ratio of skilled to unskilled labor in the native relative to the immigrant populations. For both natives and immigrants, the ratio of skilled to unskilled labor is measured as the ratio of the number of individuals with upper-secondary or tertiary education to the number of individuals with lower-secondary education. The RSC uses data on the stock of immigrants and natives in 2002-2003 (OECD, 2005). benefits is per capita social expenditure in 1998 (at constant 1995 prices and PPP-adjusted).

$g d p$ is per capita GDP in 2002 (PPP, 2000 international dollars) and is from the World Development Indicators (World Bank).

same regressors as in regression 1 , table 7 , with pro-trade dummy as the dependent variable. ${ }^{58}$ Our goal is to investigate whether cleavages in trade attitudes mirror those for immigration. If that was the case, we might worry that our results are not driven by the welfare-state channel since trade openness is not likely to have as large an impact as immigration on public finances in advanced countries. ${ }^{59}$ In any case, even if this were not true-that is, trade liberalization significantly affects the welfare state 60 -we do not expect the effect of public-finance issues on trade preferences to be a function of the relative skill composition of natives to immigrants. As our results on trade preferences in regression 6 of table 7 show, the effects estimated in our previous regressions are indeed specific to immigration attitudes.

Finally, the results based on the ESS data set offer empirical evidence that is remarkably similar to what we found using the ISSP survey. As the estimates in table 9 show, individual attitudes toward immigrants in the ESS sample are on average consistent with the tax adjustment

\footnotetext{
${ }^{58}$ See definition of pro-trade dummy in the footnote to table 1.

${ }^{59}$ As Hanson, Scheve, and Slaughter (2007) note, "Immigrants may pay taxes, may receive public services, and may vote over tax and spending choices. Imports, obviously, do none of these things" (p. 1). In general, the fiscal costs of trade adjustment assistance programs are limited.

${ }^{60} \mathrm{An}$ alternative view is that trade liberalization has a considerable impact on the welfare state since the demand for social insurance increases with free trade (Rodrik, 1998).
}

model (the coefficient on income is positive and negative given, respectively, skilled and unskilled migration) and with labor market determinants (the coefficient on education is negative and positive given, respectively, skilled and unskilled migration). To conclude, given the difference in country coverage of the sample, in the questionnaire date and wording of the immigration question relative to the ISSP survey, the ESS results represent an important robustness check of the conclusions of this paper.

\section{Conclusions}

In this paper we have developed a simple theoretical framework to study the effect of a redistributive welfare state on individual attitudes toward immigration. We have highlighted that this effect depends in a fundamental way on how the welfare state adjusts to an inflow of foreign workers. In particular, we have shown that high-income individuals are worse hit by unskilled immigration only if taxes are raised to maintain per capita transfers unchanged (tax adjustment model). At the same time, agents at the bottom of the income distribution will suffer more with unskilled immigration if tax rates are kept constant and the adjustment is carried out through a reduction in the per capita transfers (benefit adjustment model). These relationships are reversed in the case of skilled migration.

Using two different surveys of individual attitudes toward 
migrants, we have brought the predictions of the two models to the data. Differently from the existing literature, we have carried out our investigation taking full advantage of both the cross-country and individual-level variation in the data. The results we obtain are on average consistent with the tax adjustment model, that is, with an adjustment to immigration that is carried out through changes in the tax rates. In particular, we find that high-income individuals oppose immigration through this channel in countries where immigration is unskilled and therefore a net burden to the welfare state. The data suggest an opposite pattern when migration is skilled. In this case the correlation between income and pro-immigration preferences is positive, which is consistent with a situation where migrants are perceived as net contributors to the welfare state.

More generally, we find that the income-distribution effects of immigration as perceived by individuals are less pronounced than pointed out in the existing literature. Individual skill and income have opposite effects on individual attitudes. Since skill and income are positively correlated, the labor market and welfare-state channels partially offset each other. For example, the very same skilled and highincome German businessman may feel ambivalent regarding the arrival of unskilled immigrants since he might benefit from hiring them (labor market complementarity) but be hurt by paying their way through the welfare state.

Finally, in our model we have used the skill composition of natives relative to immigrants to capture whether immigration will be a net burden or contribution for the public finances of the host countries. In practice, while unskilled labor flows are likely to represent a net burden, the same young immigrants have been portrayed by some as the answer to the deteriorating conditions of the welfare state in destinations with aging populations. In particular, in many OECD economies, pay as you go social security systems are the main vehicle through which retirement benefits are paid. Thus, another interesting question to consider is how differences in the age structure and fertility rates of natives relative to immigrants can affect individual attitudes toward immigration. This question represents an important direction for future research.

\section{REFERENCES}

Ai, C., and E. C. Norton, "Interaction Terms in Logit and Probit Models," Economics Letters 80 (2003), 123-129.

Alesina, A., and E. La Ferrara, "Preferences for Redistribution in the Land of Opportunities," Journal of Public Economics 89 (2005), 897 931.

Berry, R. A., and A. Soligo, "Some Welfare Effects of International Migration," Journal of Political Economy 77 (1969), 778-794.

Blanchflower, D., and A. Oswald, "Well-Being over Time in Britain and the USA," Journal of Public Economics 88 (2004), 1359-1386.

Boeri, T., G. Hanson, and B. McCormick, Immigration Policy and the Welfare System (Oxford: Oxford University Press, 2002).

Borjas, G. J., "The Economic Benefits from Immigration," Journal of Economic Perspectives 9:2(1995), 3-22.

"The Economic Analysis of Immigration" (pp. 1697-1760), in O. C. Ashenfelter and D. Card (Eds.), Handbook of Labor Economics (Amsterdam: North-Holland, 1999a).
Heaven's Door: Immigration Policy and the American Economy (Princeton, NJ: Princeton University Press, 1999b).

Borjas, G. J., and L. Hilton, "Immigration and the Welfare State: Immigrant Participation in Means-Tested Entitlement Programs," Quarterly Journal of Economics 111 (1996), 575-604.

Campos, N., and F. Coricelli, "Growth in Transition," Journal of Economic Literature 40 (2002), 793-836.

Caplan, B., "Systematically Biased Beliefs about Economics," Economic Journal 112 (2002), 433-458.

Casarico, A., and C. Devillanova, "Social Security and Migration with Endogenous Skill Upgrading," Journal of Public Economics 87 (2003), 773-797.

Chamberlain, G., "Panel Data" (pp. 1247-1318), in Z. Griliches and M. Intriligator (Eds.), Handbook of Econometrics (Amsterdam: NorthHolland, 1984).

Cortes, P., "The Effect of Low Skilled Immigration on U.S. Prices: Evidence from CPI Data," University of Chicago, Graduate School of Business mimeograph (2006).

Daveri, F., and G. Tabellini, "Unemployment and Taxes: Do Taxes Affect the Rate of Unemployment?" Economic Policy 15 (2000), 48-104.

Dustmann, C., and I. Preston, "Is Immigration Good or Bad for the Economy? Analysis of Attitudinal Responses," Research in Labor Economics 24 (2004a), 3.

"Racial and Economic Factors in Attitudes to Immigration," UCL mimeograph (2004b)

Espenshade, T. J., and K. Hempstead, "Contemporary American Attitudes toward U.S. Immigration," International Migration Review 30 (1996), 535-570.

Hainmueller, J., and M. J. Hiscox, "Educated Preferences: Explaining Attitudes toward Immigration in Europe," International Organization 61 (2007), 399.

Hanson, G. H., Why Does Immigration Divide America? Public Finance and Political Opposition to Open Borders (Washington, DC: Institute for International Economics, 2005).

Hanson, G. H., K. Scheve, and M. J. Slaughter, "Individual Preferences over High Skilled Immigration in the United States," University of California, San Diego, mimeograph (2005).

"Public Finance and Individual Preferences over Globalization Strategies," Economics and Politics 19 (2007), 1-33.

Haupt, A., and W. Peters, "Public Pension and Voting over Immigration," Public Choice 95 (2003), 403-413.

Jovell, R., et al., "European Social Survey 2003: Technical Report," City University of London, Centre for Comparative Social Studies mimeograph (2003).

Kessler, A., "Immigration, Economic Insecurity, and the 'Ambivalent' American Public," Center for Comparative Immigration Studies working paper no. 41 (2001).

Luttmer, E., "Group Loyalty and the Taste for Redistribution," Journal of Political Economy 109 (2001), 500-528.

Mayda, A. M., "Who Is Against Immigration? A Cross-Country Investigation of Individual Attitudes toward Immigrants," this REVIEW 88 (2006), 510-530.

Mendoza, E., A. Razin, and L. Tesar, Effective Tax Rates in Macroeconomics: Cross Country Estimates of Tax Rates on Factor Income and Consumption," Journal of Monetary Economics 34 (1994), 297-323.

Milesi-Ferretti, G. M., E. Mendoza, and P. Asea, "On the Ineffectiveness of Tax Policy in Altering Long Run Growth: Harberger Superneutrality Conjecture," Journal of Public Economics 66 (1997), 99126.

Mirrlees, J. A., "An Exploration in the Theory of Optimum Income Taxation," Review of Economic Studies 38 (1971), 175-208.

OECD, "International Migration Statistics for OECD Countries," data set (1997).

The Tax/Benefit Position of Employees: 1995-1996 (Paris: OECD, 1998).

Trends in International Migration (Paris: OECD, 2005).

O'Rourke, K. H., and R. Sinnott, "The Determinants of Individual Attitudes towards Immigration," European Journal of Political Economy 22 (2006), 838-861.

Ortega, F., "Immigration Policy and Skill Upgrading," Journal of Public Economics 89 (2005), 1841-1863. 
Razin, A., and E. Sadka, "Migration and Pension with International Capital Mobility," Journal of Public Economics 74 (1999), 141150.

Razin, A., E. Sadka, and P. Swagel, "Tax Burden and Migration: A Political Economy Theory and Evidence," Journal of Public Economics 85 (2002), 167-190.

Rodrik, D., "Political Economy of Trade Policy" (pp. 1457-1494), in G. Grossman and K. Rogoff (Eds.), Handbook of International Economics, vol. 3 (Amsterdam: North-Holland Elsevier Science, 1995).

Has Globalization Gone Too Far? (Washington, DC: Institute for International Economics, 1997)

Scheve, K. F., and M. J. Slaughter, "Labor Market Competition and Individual Preferences over Immigration Policy,” this REVIEW 83 (2001), 133-145.

Smith, J. P., and B. Edmonston (Eds.), The New Americans: Economic, Demographic, and Fiscal Effects of Immigration (Washington, DC: National Research Council, National Academy Press, 1997).

SOPEMI, Trends in International Migration 2004 Edition (Paris: OECD, 2005).

Storesletten, K., "Sustaining Fiscal Policy through Immigration," Journal of Political Economy 108 (2000), 300-324.

Watts, J. R., Immigration Policy and the Challenge of Globalization (Ithaca, NY: Cornell University Press, 2002).

\section{APPENDIX}

\section{Proof of Proposition 1}

Proof. Notice that, absent labor market effects and holding the demogrant constant, equation (9) implies

$$
\frac{\hat{I}}{d \pi}=-\frac{G_{\tau}}{b+G(1-\tau)}\left[\frac{\hat{\tau}}{d \pi}\right] .
$$

From equation (11) we know that if immigration is unskilled, $\frac{\hat{t}}{d \pi}>0$ and thus $\frac{1}{d \pi}<0$. The opposite is true if immigration is skilled and $\eta_{E}<\eta_{E}^{*}$. To assess the effect of different individual income levels, notice that

$$
\frac{\partial\left(\frac{\hat{l}}{d \pi}\right)}{\partial G}=-\frac{\hat{\tau}}{d \pi}\left\{\frac{b \tau}{[b+G(1-\tau)]^{2}}\right\} .
$$

If immigration is unskilled, which implies $\frac{\hat{\tau}}{d \pi}>0$, then $\frac{\partial\left(\frac{\hat{l}}{d \pi}\right)}{\partial G} \leq 0$. On the other hand, if immigration is skilled, from equation (11) we know that $\frac{\hat{f}}{d \pi}<0$ as long as $\eta_{E}<\frac{\left(1-\beta_{v}\right)\left(\phi_{\nu}-\eta_{v}\right)}{\left(1-\psi_{v}\right)}$ and, as a result, $\frac{\partial\left(\frac{\hat{l}}{d \pi}\right)}{\partial G} \geq 0$.

\section{Proof of Proposition 2}

Proof. Without labor market effects and holding the tax rates unchanged, equation (9) becomes

$$
\frac{\hat{I}}{d \pi}=\frac{b_{d \pi}^{\frac{b}{d \pi}}}{b+G(1-\tau)} .
$$

To assess the effects of different individual income levels, notice that

$$
\frac{\partial\left(\frac{\hat{l}}{d \pi}\right)}{\partial G}=-\frac{b \frac{b}{d \pi}(1-\tau)}{[b+G(1-\tau)]^{2}} .
$$

We have seen that with a redistributive tax system, unskilled immigration leads to a reduction in the per capita transfers $\left(\frac{b}{d \pi}<0\right)$ therefore $\frac{\partial\left(\frac{l}{d \pi}\right)}{\partial G} \geq$

0 . With skilled immigration, $\frac{\hat{b}}{d \pi}>0$ as long as $\eta_{E}<\frac{\left(1-\beta_{v}\right)\left(\phi_{\psi}-\eta_{w}\right)}{\left(1-\psi_{\psi}\right)}$ and therefore $\frac{\partial\left(\frac{\hat{l}}{d \pi}\right)}{\partial G}<0$. 